This is the final peer-reviewed accepted manuscript of:

G. Rossi, L. Pasquini, D. Catone, A. Piccioni, N. Patelli, A. Paladini, S. Caramori, A. Molinari, P. O'Keeffe, and F.Boscherini, Charge carrier dynamics and visible light photocatalysis in vanadium-doped TiO2 nanoparticles, Applied Catalysis B:

Environmental 237, 603 - 612 (2018). DOI: 10.1016/j.apcatb.2018.06.011.

The final published version is available online at:

http://dx.doi.org/10.1016\%2Fj.apcatb.2018.06.011

(C) 2018. This manuscript version is made available under the Creative Commons AttributionNonCommercial-NoDerivs (CC BY-NC-ND) License 4.0 International

(http://creativecommons.org/licenses/by-nc-nd/4.0/) 


\section{Charge carrier dynamics and visible light photocatalysis in vanadium-doped $\mathrm{TiO}_{2}$ nanoparticles}

Giacomo Rossi, ${ }^{1}$ Luca Pasquini, ${ }^{1, \S}$ Daniele Catone,${ }^{2}$ Alberto Piccioni, ${ }^{1}$ Nicola Patelli, ${ }^{1}$ Alessandra Paladini, ${ }^{3}$ Alessandra Molinari, ${ }^{4}$ Stefano Caramori, ${ }^{4}$ Patrick O' Keeffe, ${ }^{3}$ Federico Boscherini ${ }^{1}$

1 - Department of Physics and Astronomy, Alma Mater Studiorum Università di Bologna, V. C. Berti-Pichat 6/2, 40127 Bologna, Italy

2 - CNR-ISM, Division of Ultrafast Processes in Materials (FLASHit), Area della Ricerca di Roma Tor Vergata, Via del Fosso del Cavaliere 100, Rome, Italy

3 - CNR-ISM, Division of Ultrafast Processes in Materials (FLASHit), Area della Ricerca di Roma 1, MonterotondoScalo, Italy

4 - Department of Chemical and Pharmaceutical Sciences, University of Ferrara, Via Luigi Borsari 46, 44121 Ferrara, Italy

$\S$ corresponding author: luca.pasquini@unibo.it

Abstract: Vanadium-doped $\mathrm{TiO}_{2}$ nanoparticles $\left(\mathrm{V}-\mathrm{TiO}_{2} \mathrm{NPs}\right)$ with a $\mathrm{V} / \mathrm{Ti}$ ratio of 3.0 at. \% were prepared by gas-phase condensation and subsequent oxidation at elevated temperature. Both photocatalytic activity for $-\mathrm{NO}_{2}$ reduction and photoelectrochemical water splitting were induced by V-doping in the visible spectral range $\lambda>450 \mathrm{~nm}$, where undoped $\mathrm{TiO}_{2} \mathrm{NPs}$ are completely inactive. The photocatalytic properties were correlated with the ultrafast dynamics of the photoexcited charge carriers studied by femtosecond transient absorption (TA) spectroscopy with three different excitation wavelengths, i.e. $\lambda_{e}=330,400$, and $530 \mathrm{~nm}$. Only in V-doped NPs, the photoexcitation of electrons into the conduction band by sub-bandgap irradiation $\left(\lambda_{\mathrm{e}}=530 \mathrm{~nm}\right)$ was detected by TA spectroscopy. This observation was associated with electronic transitions from an intra-gap level localized on $\mathrm{V}^{4+}$ cations. The photoexcited electrons subsequently relaxed, with characteristic times of 200-500 ps depending on $\lambda_{\mathrm{e}}$, into Ti-related surface traps that possessed suitable energy to promote $-\mathrm{NO}_{2}$ reduction. The photoexcited holes migrated to long-lived surface traps with sufficient overpotential for the oxidization of both 2-propanol and water. On the basis of TA spectroscopy and photocurrent measurements, the position of the dopant-induced intra-gap level was estimated as 2.2 $\mathrm{eV}$ below the conduction band minimum.

Keywords: Photocatalysis; $\mathrm{TiO}_{2}$; transient absorption spectroscopy; $\mathrm{NO}_{2}$ reduction; vanadium doping.

\section{Introduction}

$\mathrm{TiO}_{2}$ is one of the most studied wide band gap oxide semiconductors due to its photocatalytic properties, opening the way to various applications such as hydrogen production from water and environmental cleaning (air and water) [1-5]. However, because of its wide band gap (3.0 eV for rutile and $3.2 \mathrm{eV}$ for anatase [4]), only a small fraction of the solar spectrum, i.e. UV light (3-5\% of total), can be used for photocatalytic processes.

A widely investigated strategy to shift the optical absorption of $\mathrm{TiO}_{2}$ towards the visible region is doping with ionic species [6]. However, the enhanced optical absorption does not always correspond to a photocatalytic activity in a previously inactive spectral range. In fact, absorption from intra-gap states may not generate sufficiently strong oxidants for the desired reaction. This means that the absorption spectrum of a photocatalyst does not necessarily match its photocatalytic activity spectrum. A clear mechanistic view of the dopant role in photocatalysis is far from being established. The dopants in $\mathrm{TiO}_{2}$ can be classified into: 1) nonmetal dopants $(\mathrm{C}, \mathrm{N}, \mathrm{F}, \mathrm{S})[7-9]$ and 2 ) metal dopants, especially $3 \mathrm{~d}$ transition metals and noble metals (Pt, $\mathrm{Cu}$ ) [10-12]. Metal dopants can influence $\mathrm{TiO}_{2}$ photocatalysis by three principal mechanisms: i) improvement of the electron-hole separation (beneficial) by selective trapping, usually at low doping concentration $(<1$ at.\%) $[6,13]$; ii) reduction of carriers lifetime (detrimental) due to the dopant that acts as a recombination center $[2,14]$, and iii) enhancement of optical absorption in the visible range. 
The first two mechanisms are not expected to modify the spectral range of photoactivity. In this work, we address in particular the third mechanism and aim at achieving both optical absorption and photocatalytic activity in a visible spectral range $(\lambda>450 \mathrm{~nm})$ where pure $\mathrm{TiO}_{2}$ is completely inactive. We investigate undoped $\mathrm{TiO}_{2}$ nanoparticles (NPs) and vanadium-doped $\mathrm{TiO}_{2}\left(\mathrm{~V}-\mathrm{TiO}_{2}\right) \mathrm{NPs}$. V-doping is known to induce an absorption red-shift and has been reported to improve the photocatalytic degradation of water pollutants under solar irradiation [15-19]. Several studies have shown that $V$ induces electronic states within the band gap of $\mathrm{TiO}_{2}$. Umebayashi et al. [20] found by $a b$-initio calculations that $V$ generates a narrow band of partially filled levels about $0.7 \mathrm{eV}$ below the conduction band minimum (CBM) of $\mathrm{TiO}_{2}$. This estimate was confirmed by Patel et al. [16], whereas Osorio-Guillén et al. calculated a deeper level at $1.36 \mathrm{eV}$ below the CBM [21]. At present, it is not clear whether the photocatalytic activity extends into a spectral region inaccessible to pure $\mathrm{TiO}_{2}$. Answering this question is one of the purposes of the present paper.

Time-resolved pump-probe optical spectroscopy is a key tool to elucidate the charge carrier dynamics that underlie photocatalysis. Several investigations were performed on undoped $\mathrm{TiO}_{2}$ using ultrabandgap excitation $\left(\lambda_{e} \approx 330-360 \mathrm{~nm}\right.$ ) [22-32]. Photoexcitation leads to the almost instantaneous formation of free charge carriers, some of which are rapidly trapped near surface sites. The spectroscopic signature of free and trapped carriers has been studied by transient absorption (TA) spectroscopy by Yoshihara et al. [26] who showed that the response is composed of three positive features ascribed to trapped holes (TH), trapped electrons (TE) and free electrons in the conduction band (FE). From an atomistic point of view, hole trapping is due to the formation of $\mathrm{O}^{-}$or $\mathrm{O}_{3}^{-}$according to $\mathrm{O}^{2-}+\mathrm{h}^{+} \rightarrow \mathrm{O}^{-}$or $\mathrm{O}^{2-}+\mathrm{O}_{2}+\mathrm{h}^{+} \rightarrow \mathrm{O}_{3}^{-}$[32-34], while electron trapping is due to the $\mathrm{Ti}^{4+}+\mathrm{e}^{-} \rightarrow \mathrm{Ti}^{3+}$ process [35]. The rise time of signals related to the three mentioned components allows to explore the trapping dynamics of the respective charge carriers. The trapping time constants associated with the electron signals reported in the literature are relatively similar: $\sim 180 \mathrm{fs}$ according to Skinner et al. [36], $\sim 260 \mathrm{fs}$ (Yang and Tamai [27]) and $\sim 170 \mathrm{fs}$ (Tamaki et al. [28]). However, since the TE and FE signals are superimposed, it is not clear how to associate these times to the different physical processes. There is less consensus on the hole trapping times: Yang and Tamai quote a value $<50 \mathrm{fs}$ while Tamaki et al. estimate it to be $\sim 220 \mathrm{fs}$. After their initial formation, the trapped and free carriers decay by various processes on the timescale of $10-100 \mathrm{~s}$ of ps or more, depending on the carrier density and the specific system investigated. The time decay of the spectral features is related to the dynamics of the charge carriers.

Ultrafast spectroscopy was also applied to track photoexcited charge carriers in doped $\mathrm{TiO}_{2}$ [37-42]. Ikeda et al observed a second-order kinetics due to electron-hole recombination, the rate constant of which increases with increasing dopant concentration [42]. Similarly, in $\mathrm{TiO}_{2}-\mathrm{M}-\mathrm{TiO}_{2}$ multilayer films ( $\mathrm{M}=\mathrm{Co}$ or W) Sun et al. [37] showed that doping does not change the wavelength dependence of the TA spectra but that it induces a faster decay of the spectral features.

Studies of the local structure of $\mathrm{V}$ dopants in $\mathrm{TiO}_{2}$ provide the essential prerequisite for an understanding of the optical properties and of the charge carrier dynamics. We have recently published X-ray Absorption Fine Structure (XAFS) studies which demonstrate that $\mathrm{V}$ always occupies a substitutional site in $\mathrm{V}-\mathrm{TiO}_{2} \mathrm{NPs}^{\text {[43] }}$ and in $\mathrm{V}-\mathrm{TiO}_{2}$ thin films [44] irrespective of whether they have mainly anatase or rutile structure. By exploiting the chemical sensitivity of XAFS, we have also performed a differential illumination High Energy Resolution Fluorescence Detected (HERFD) - X-ray Absorption Near Edge Structure (XANES) experiment on V-TiO ${ }_{2} \mathrm{NPS}$ [45]. This experiment demonstrated that visible light $(\lambda=532 \mathrm{~nm})$ absorption is mainly due to electron transfer from $V$ dopant sites to Ti defective ones. By means of a quantitative analysis, a long electron lifetime in the defective sites of $\sim 0.8 \mathrm{~ms}$ was estimated. This work followed our previous study of plasmon-induced hot electron transfer in $\mathrm{Au}-\mathrm{TiO}_{2}$ nanostructures [46]. In the context of X-ray spectroscopic investigations we note that electron transfer to defective Ti sites in undoped or dye-sensitized $\mathrm{TiO}_{2} \mathrm{NPs}_{\text {s }}$ has been demonstrated by time resolved methods on the 100 ps time scale by Rittmann Frank et al. [47] and more recently on the $100 \mathrm{fs}$ time scale by Obara et al. [48]. 
In this paper, we employ TA spectroscopy with sub $100 \mathrm{fs}$ time resolution to study electron and hole dynamics after photoexcitation at three different wavelengths $\left(\lambda_{e}=330,400,530 \mathrm{~nm}\right)$. We correlate the peculiar TA features of undoped and V-doped $\mathrm{TiO}_{2} \mathrm{NPs}$ to their photoactivity at different excitation wavelengths. We will show that $\mathrm{V}$-doped $\mathrm{TiO}_{2}$ NPs exhibit a clear photoactivity, both for nitro group reduction and for photoelectrochemical water splitting, in the visible spectral range $(\lambda>450 \mathrm{~nm})$ where undoped $\mathrm{TiO}_{2}$ is completely inactive.

\section{Experimental}

$\mathrm{TiO}_{2}$ and $\mathrm{V}-\mathrm{TiO}_{2} \mathrm{NPs}$ were grown via gas phase condensation. The evaporation material was either pure $\mathrm{Ti}$ in powder form or a Ti-V powder mixture. Thermal evaporation was carried out in a ultra-high vacuum chamber filled with $266 \mathrm{~Pa}$ of He. The NPs, which nucleated by condensation of the supersaturated metal vapors, were collected via thermophoresis on a rotating steel cylinder cooled by liquid nitrogen. After the evaporation, pure $\mathrm{O}_{2}$ was admitted into the chamber up to a final pressure of $2.6 \mathrm{kPa}$, yielding oxidized dark-gray NPs with an amorphous structure. After annealing at $400{ }^{\circ} \mathrm{C}$ in air for 6 hours, the undoped NPs turned white, while the V-doped NPs appeared yellowish. X-ray powder diffraction (XRD) and transmission electron microscopy (TEM) showed that complete crystallization took place [45]. The X-ray powder diffraction patterns (Figure S1 of the supplemental material) indicated that $\mathrm{TiO}_{2}$ and $\mathrm{V}-\mathrm{TiO}_{2} \mathrm{NPs}$ had a similar phase composition with about $75 \mathrm{wt} \%$ rutile, $15 \mathrm{wt} \%$ anatase, and $5 \mathrm{wt} \%$ brookite. These $\mathrm{TiO}_{2}$ polymorphs were finely mixed at the nanoscale level as shown by high-resolution TEM [45]. The average size of the NPs was $12 \pm 1 \mathrm{~nm}$ according to TEM analysis. The $\mathrm{V} / \mathrm{Ti}$ ratio estimated by energy dispersive $\mathrm{X}$-ray spectroscopy in a scanning electron microscope was $3.0 \pm 0.5$ at. \%. Further information about the deposition procedure can be found in previous publications $[43,45]$.

Diffuse reflectance (DR) spectra were collected by a Perkin Elmer Lambda 45 double beam spectrophotometer equipped with an RSA-PE-20 integrating accessory (Labsphere). The samples were measured as solid mixtures in a matrix of ground $\mathrm{NaCl}$. Prior to measurement, a blank of pure $\mathrm{NaCl}$ was recorded as a reference. The UV-vis absorbance, reported in Figure S2 of the supplementary material, were obtained by applying the Kubelka-Munk function to DR spectra.

In order to prepare suitable samples for the TA measurements, the NPs were suspended in a 70/30 bi-distilled water/acetic acid solution with overall concentration of $1 \mathrm{mg} \mathrm{NPs} / 1 \mathrm{ml}$ solution. The obtained stable suspension was deposited on UV transparent quartz substrates via drop casting. The thickness of the samples was increased until an optical density (OD) of 1.0 at $\lambda=400 \mathrm{~nm}$ was achieved.

Ultrafast TA spectroscopy measurements in the pump $\left(\lambda_{e}\right)$ and probe $\left(\lambda_{p}\right)$ scheme were performed with a laser system consisting of a chirped pulse amplifier seeded by a Ti:Sa oscillator. The pump pulses were produced either by frequency doubling of the $800 \mathrm{~nm}$ fundamental $(400 \mathrm{~nm})$ or by using the output of an optical parametric amplifier ( 330 and $530 \mathrm{~nm}$ ). The white light probe ( $350-800 \mathrm{~nm}$ ), on the other hand, was generated in a commercial TA spectrometer (FemtoFrame II, IB Photonics) employing a split beam configuration in which $50 \%$ of the white light passes through the sample while the remainder is used as a reference to account for pulse to pulse fluctuations in the white light generation. The pump pulse is loosely focused (circular spot of diameter $=500 \mu \mathrm{m}$ ) onto the sample with an energy density from $350 \mu \mathrm{J} / \mathrm{cm}^{2}$ to 7 $\mathrm{mJ} / \mathrm{cm}^{2}$; unless otherwise noted the energy density employed was $1.8 \mathrm{~mJ} / \mathrm{cm}^{2}$. The spot diameter of the probe pulse is much smaller (approx. $150 \mu \mathrm{m}$ ) and its delay time with respect to the pump pulse is scanned in time by varying the length of its optical path. The instrument response function was measured to be approximately $80 \mathrm{fs}$. All measurements were performed in air at room temperature. Further details of the set-up can be found in previous publications $[49,50]$.

The photocatalytic activity of the NPs exposed to visible light irradiation was tested by monitoring the reduction of the $\mathrm{NO}_{2}$ group in 4- nitrobenzaldehyde $\left(\mathrm{NO}_{2}-\mathrm{C}_{6} \mathrm{H}_{4}-\mathrm{CHO}\right)$. To this purpose, a fixed amount (10 mg) of NPs was suspended in $3 \mathrm{~mL}$ of a $9 \times 10^{-5} \mathrm{M}$ solution of $\mathrm{NO}_{2}-\mathrm{C}_{6} \mathrm{H}_{4}-\mathrm{CHO}$ in a $\mathrm{CH}_{3} \mathrm{CN} / \mathrm{C}_{3} \mathrm{H}_{8} \mathrm{O}(4 / 1)$ mixture. The suspension was degassed by bubbling $\mathrm{N}_{2}$ for 20 minutes. Afterwards it was irradiated by a LOT-Oriel solar 
simulator, equipped with both an AM1.5G filter and a cut-off filter $\lambda>450 \mathrm{~nm}$. At desired time intervals, the irradiation was stopped and after centrifugation the absorbance values of the liquid phase at $264 \mathrm{~nm}$ and at $312 \mathrm{~nm}$ were recorded by a Jasco V570 spectrophotometer. Control experiments were carried out keeping the samples in the dark for the required period. Moreover, a solution ( $3 \mathrm{~mL}$ ) of a $\mathrm{CH}_{3} \mathrm{CN}_{2} \mathrm{C}_{3} \mathrm{H}_{8} \mathrm{O}(4 / 1)$ mixture containing $\mathrm{NO}_{2}-\mathrm{C}_{6} \mathrm{H}_{4}-\mathrm{CHO}\left(9 \times 10^{-5} \mathrm{M}\right)$ was irradiated in the absence of photocatalyst.

Incident photon-to-current conversion efficiency (IPCE) spectra were measured in $\mathrm{KOH}(0.1 \mathrm{M}, \mathrm{pH}=13)$ under a bias potential of $0.5 \mathrm{~V}$ vs saturated calomel electrode (SCE). For the realization of the photoanodes, $10 \mathrm{mg}$ of NPs were dispersed in $0.2 \mathrm{ml}$ of a $1 / 1$ distilled water/acetylacetone solution. The resulting paste was uniformly distributed by sliding a glass rod onto a glass substrate coated by a $100 \mathrm{~nm}$ thick layer of indium tin oxide (ITO glass). The ITO sheet resistance was $20 \Omega$ /square. The ITO glass was previously treated with an acidic solution to make its surface more hydrophilic and to avoid the presence of areas uncoated by the NPs. Finally, the photoanodes were annealed at $400^{\circ} \mathrm{C}$ in air for 2 hours. The final thickness of the NPs layer on ITO was $1 \mu \mathrm{m}$. The photoanodic current was recorded from 350 to $500 \mathrm{~nm}$ with $5 \mathrm{~nm}$ steps using a PGSTAT204 electrochemical workstation. The PGSTAT204 output signal, proportional to the photoanodic current, was fed into a lock-in amplifier and the incident light was chopped at $2 \mathrm{~Hz}$. The incident monochromatic irradiance was measured with a calibrated pyroelectric sensor. IPCE was calculated according to: $\operatorname{IPCE}(\%)=1.24$. $10^{3} J_{\lambda}\left(\mu \mathrm{A} \mathrm{cm}^{-2}\right) /\left[\lambda(\mathrm{nm}) \cdot P_{\lambda}\left(\mathrm{W} \mathrm{m}^{-2}\right)\right]$, where $J_{\lambda}$ and $P_{\lambda}$ are the photocurrent density and incident radiant power density at wavelength $\lambda$.

\section{Results and Discussion}

\subsection{Transient absorption spectroscopy: ultrabandgap $(330 \mathrm{~nm})$ excitation}

We start by reporting and discussing measurements performed with ultrabandgap excitation, $\lambda_{e}=330 \mathrm{~nm}$. The TA spectra for undoped and V-doped NPs are reported in Figure 1 as a function of the probe wavelength $\left(\lambda_{p}\right)$ for selected time delays in the range $t=0.2-250 \mathrm{ps}$ after the pump pulse. The same data are reported in 2 dimensions as a function of $\left(\lambda_{p}, t\right)$ in Figure S3 of the supplemental material. The presence of two bands centered at approximately $400 \mathrm{~nm}$ and $730 \mathrm{~nm}$ is apparent. The two samples have spectral features as a function of $\lambda_{p}$ which are similar to each other and to the literature results on undoped $\mathrm{TiO}_{2}$ [26], implying that V-doping does not significantly alter the state of photoexcited carriers; a significantly better spectral resolution of the present spectra compared to literature results should be pointed out.

As recently reviewed by Schneider et al. [2], several TA studies on $\mathrm{TiO}_{2}$ invariably assigned TA bands centered at $400-500 \mathrm{~nm}$ to trapped holes (TH) on the NPs surface and TA bands centered at 600-800 nm to trapped electrons (TE), also on the NPs surface. A certain spread in the energies of spectral features is present in the literature, and depends on the nature of the sample and its environment. The presence of a monotonically increasing background superposed to these bands was ascribed to intra-band transitions of free electrons (FE) photo-excited in the conduction band $[26,28]$. On these grounds, we can confidently attribute the band centered at $390-400 \mathrm{~nm}$ to the filling of trapped holes $(\mathrm{TH})$, and that centered at about $730 \mathrm{~nm}$ to the excitation of TE. The contribution of the background FE signal increases approximately as $\lambda_{p}^{1.7}$ [26]. A reliable determination and subtraction of the FE signal requires an infrared probe, i.e. $\lambda_{p}=1500-2500 \mathrm{~nm}$, which was not available in our set up. Since the separation of TE and FE signals was not possible in the present data set, in the following we will refer to the TA signal between $600 \mathrm{~nm}$ and $800 \mathrm{~nm}$ as simply due to electrons $E$ $(E=T E+F E)$. 


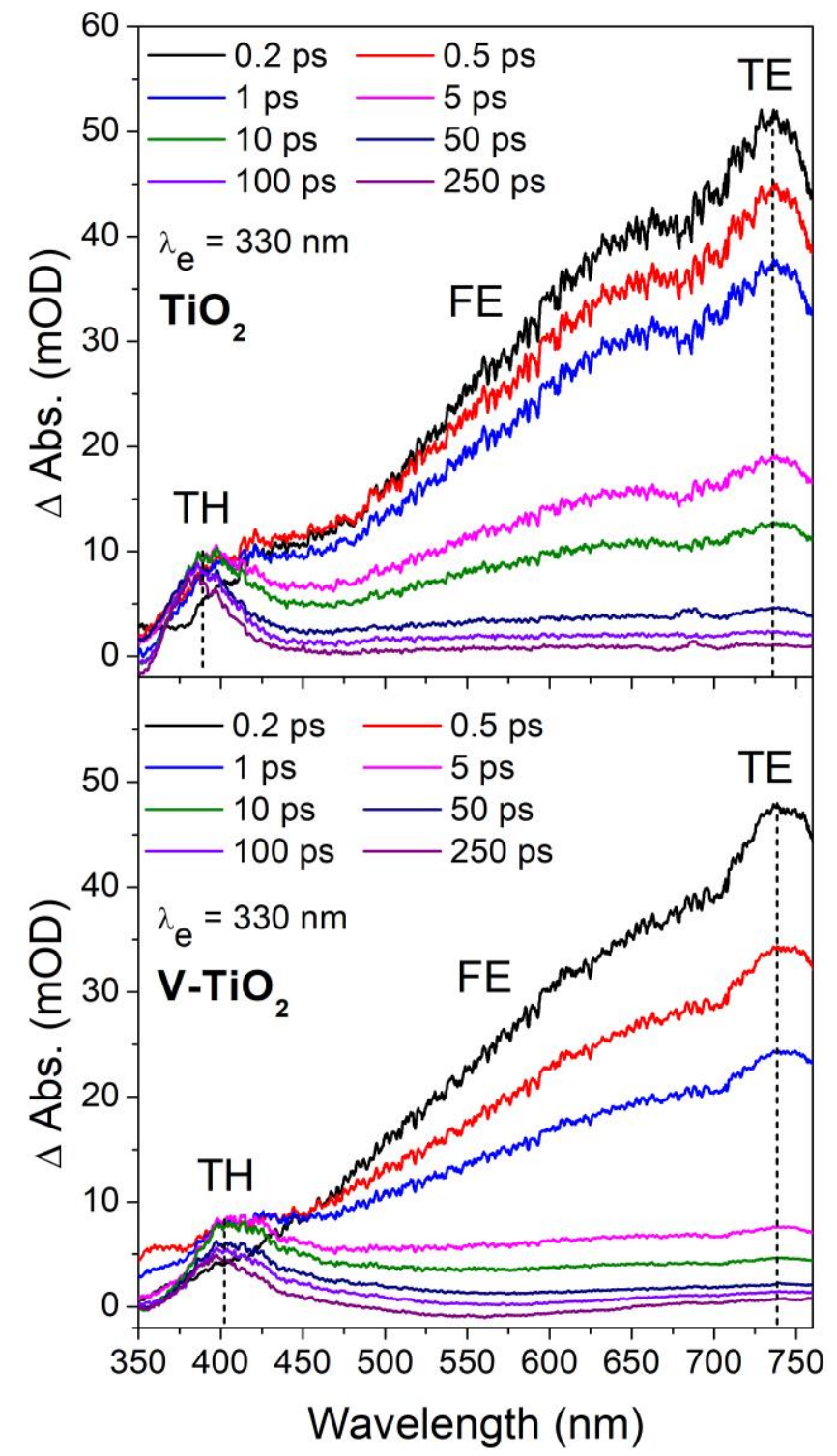

Figure 1: TA spectra of undoped (top) and V-doped (bottom) $\mathrm{TiO}_{2} \mathrm{NPs}$ with $\lambda_{e}=330 \mathrm{~nm}$ at different delay times.

Figure 1 shows that the only spectral difference introduced by doping is a small shift of the TH peak to higher wavelengths, from $\sim 390 \mathrm{~nm}$ to $\sim 400 \mathrm{~nm}$. This could be due to a small doping - induced shift of the TH states. In Figure 2 we compare the time traces of the two samples at $\lambda_{p}=730 \mathrm{~nm}$, which represents the E signal arising from both trapped and free electrons. The rise time of this signal (for both samples) is comparable to the instrumental resolution ( $~ 80 \mathrm{fs})$. This fast rise cannot be due to diffusion of electrons from the bulk to surface traps. In fact, an estimate of the diffusion time can be obtained from:

$$
\tau_{\text {diff }}=\frac{r^{2}}{\pi^{2} D}
$$

in which $r$ is the NP radius and $D$ the diffusion coefficient, which for electrons in $\mathrm{TiO}_{2}$ is $D_{e}=1 \times 10^{-6} \mathrm{~m}^{2} / \mathrm{s}$ [51]. Since the average NPs diameter is $12 \mathrm{~nm}$, the expected value for the diffusion time is $\sim 10 \mathrm{ps}$, much longer than observed. We conclude that, in the first few ps after excitation, only a small fraction of electrons, i.e. those photo-excited in near-surface sites, can migrate to and remain trapped at the surface. Therefore, the $\mathrm{E}$ signal at $\lambda_{p}=730 \mathrm{~nm}$ in the first few ps is mostly due to $\mathrm{FE}$. The initial $\triangle \mathrm{OD}$ values for the $\mathrm{TiO}_{2}$ and $\mathrm{V}$ $\mathrm{TiO}_{2} \mathrm{NPs}$ are similar ( 50mOD), indicating that the initial concentration of photo-excited electrons is not affected by doping, which is reasonable in the case of ultrabandgap excitation. The decay (Figure 2) appears 
significantly faster in $\mathrm{V}-\mathrm{TiO}_{2} \mathrm{NPs}$. We performed a fit of the time traces with a sum of a function for second order kinetics [30], which describes the fast decay in the first tens of ps, and a slow exponential decay:

$$
A(t)=\frac{A_{2 n d}}{(k C t+1)}+A_{\text {exp }} e^{-t / \tau_{e}}
$$

where the fit parameter $k C$ represents the second-order rate constant $k$ times the initial concentration $C$ of electrons. We obtained very good fits for both samples, as shown in Figure 2.

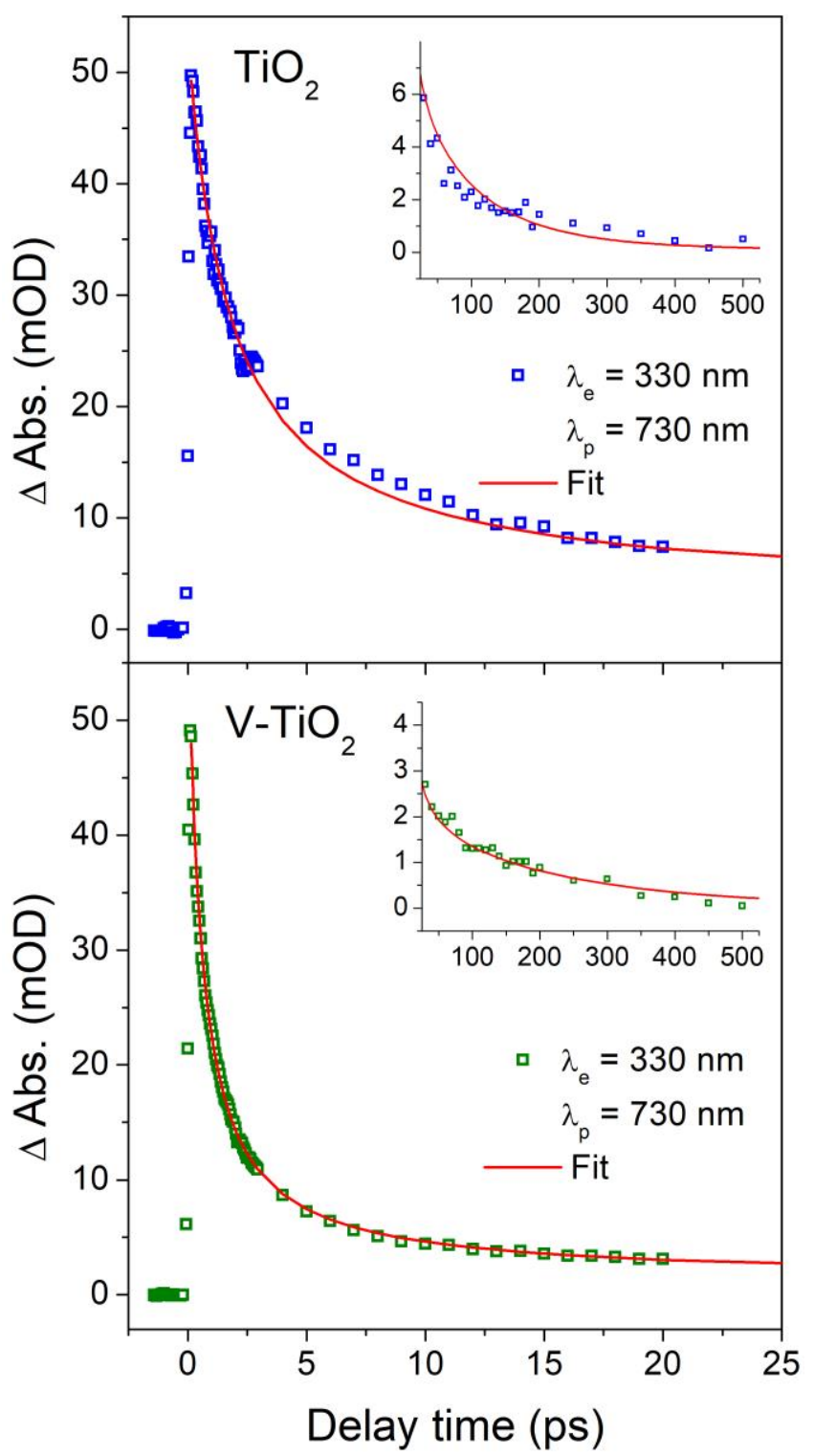

Figure 2: Comparison of the E signal time traces (at $\lambda_{p}=730 \mathrm{~nm}$ ) for undoped (top) and V-doped (bottom) $\mathrm{TiO}_{2} \mathrm{NPs}$ extracted from the data in Figure $1\left(\lambda_{\mathrm{e}}=330 \mathrm{~nm}\right)$. The best fits according to Equation 2 are displayed as red solid lines. The inset reports the same data over the extended 25-525 ps time interval.

The numerical results of the fits are summarized in Table I. The higher $k C$ value in $\mathrm{V}-\mathrm{TiO}_{2} \mathrm{NPs}$ that reflects the faster decay of the $E$ signal is in very good agreement with the dependence of the rate constant on the doping level reported by lkeda et al. [42]. The exponential decay with time constant $\tau_{e}$, needed to model the time traces at $t>100 \mathrm{ps}$, has an amplitude $A_{\text {exp }}$ much smaller than the amplitude $A_{2 n d}$ of the second-order kinetics. 
Table I: Best-fit parameters for the time traces of $E\left(\lambda_{p}=730 \mathrm{~nm}\right)$ after excitation at different wavelengths $\lambda_{e}$ according to Equation (2): amplitude $A_{2 n d}$ and rate-concentration product $k C$ of fast second-order decay, amplitude $A_{\text {exp }}$ and characteristic time $\tau_{e}$ of slow exponential decay. For $\lambda_{e}=330 \mathrm{~nm}$, we also report the characteristic times $\tau_{h 1}$ and $\tau_{h 2}$ of the exponential decay of the trapped hole signal $\left(\lambda_{p}=400 \mathrm{~nm}\right.$ ) observed in $\mathrm{V}-\mathrm{TiO}_{2} \mathrm{NPs}$. In the case $\lambda_{e}=530 \mathrm{~nm}$, the $\mathrm{E}$ signal was present only in $\mathrm{V}-\mathrm{TiO}_{2} \mathrm{NPs}$. Estimated errors are reported in brackets in units of the last digit.

\begin{tabular}{|c|c|c|c|}
\hline$\lambda_{e}(\mathrm{~nm})$ & Parameter & $\mathrm{TiO}_{2} \mathrm{NPs}$ & V-TiO 2 NPs \\
\hline \multirow{6}{*}{330} & $A_{2 n d}(\mathrm{mOD})$ & $49.6(5)$ & $58.8(3)$ \\
\hline & $k C\left(\mathrm{ps}^{-1}\right)$ & $0.56(2)$ & $1.80(2)$ \\
\hline & $A_{\text {exp }}(\mathrm{mOD})$ & $3.5(3)$ & $1.6(1)$ \\
\hline & $\tau_{e}(\mathrm{ps})$ & $210(30)$ & $220(30)$ \\
\hline & $\tau_{h 1}(\mathrm{ps})$ & no decay within 500 ps & $36(7)$ \\
\hline & $\tau_{h 2}(\mathrm{ps})$ & no decay within 500 ps & $1030(150)$ \\
\hline \multirow{4}{*}{400} & $A_{2 n d}(\mathrm{mOD})$ & $5.1(1)$ & $34.8(3)$ \\
\hline & $k C\left(\mathrm{ps}^{-1}\right)$ & $0.239(16)$ & $1.22(4)$ \\
\hline & $A_{\text {exp }}(\mathrm{mOD})$ & $1.7(1)$ & $3.9(2)$ \\
\hline & $\tau_{e}(\mathrm{ps})$ & $360(50)$ & $320(30)$ \\
\hline \multirow{4}{*}{530} & $A_{2 n d}(\mathrm{mOD})$ & \multirow{4}{*}{ TA spectra non observed } & $1.0(1)$ \\
\hline & $k C\left(\mathrm{ps}^{-1}\right)$ & & $0.8(2)$ \\
\hline & $A_{\text {exp }}(\mathrm{mOD})$ & & $0.91(5)$ \\
\hline & $\tau_{e}(\mathrm{ps})$ & & $480(90)$ \\
\hline
\end{tabular}

The time traces of the TH band are presented in Figure 3. The rise time of the TH signal was estimated by fitting the data to a step function convoluted with a Gaussian function that simulates the instrumental resolution (Figure S5). We obtained the same rise time of $230+/-90 \mathrm{fs}$ for $\mathrm{TiO}_{2} \mathrm{NPs}$ and 230 +/- $30 \mathrm{fs}$ for V$\mathrm{TiO}_{2}$ NPs, which is compatible with the data of Tamaki et al. [28]. This time interval is very similar to the diffusion time of holes from the bulk to the surface of the NPs, as estimated from Equation 1 using $D_{h}=4$. $10^{-5} \mathrm{~m}^{2} / \mathrm{s}$ [51], that is $250 \mathrm{fs}$. This is a further confirmation that this transient signal is due to TH. As already remarked for the $\mathrm{E}$ signal, the initial value of the $\mathrm{TH}$ signal is similar in $\mathrm{TiO}_{2}$ and $\mathrm{V}-\mathrm{TiO}_{2} \mathrm{NPs}$, suggesting that the dopant atoms do not significantly alter the diffusion and trapping of holes on this short time scale. However, the influence of $\mathrm{V}$-doping on the temporal dependence of the TH signal is more remarkable than for the E signal. In fact, while in $\mathrm{TiO}_{2} \mathrm{NPs}$ the TH signal remains almost constant up to $500 \mathrm{ps}$, in $\mathrm{V}-\mathrm{TiO}_{2} \mathrm{NPs}$ it decays to $50 \%$ of the initial value in $\sim 300$ ps (Figure 3a). The TH time trace was fitted to a sum of two exponentials with characteristic times $\tau_{h 1}=36 \pm 7 \mathrm{ps}$ and $\tau_{h 2}=1030 \pm 150 \mathrm{ps}$, as shown in Figure $3 \mathrm{a}$ and reported in Table I. 

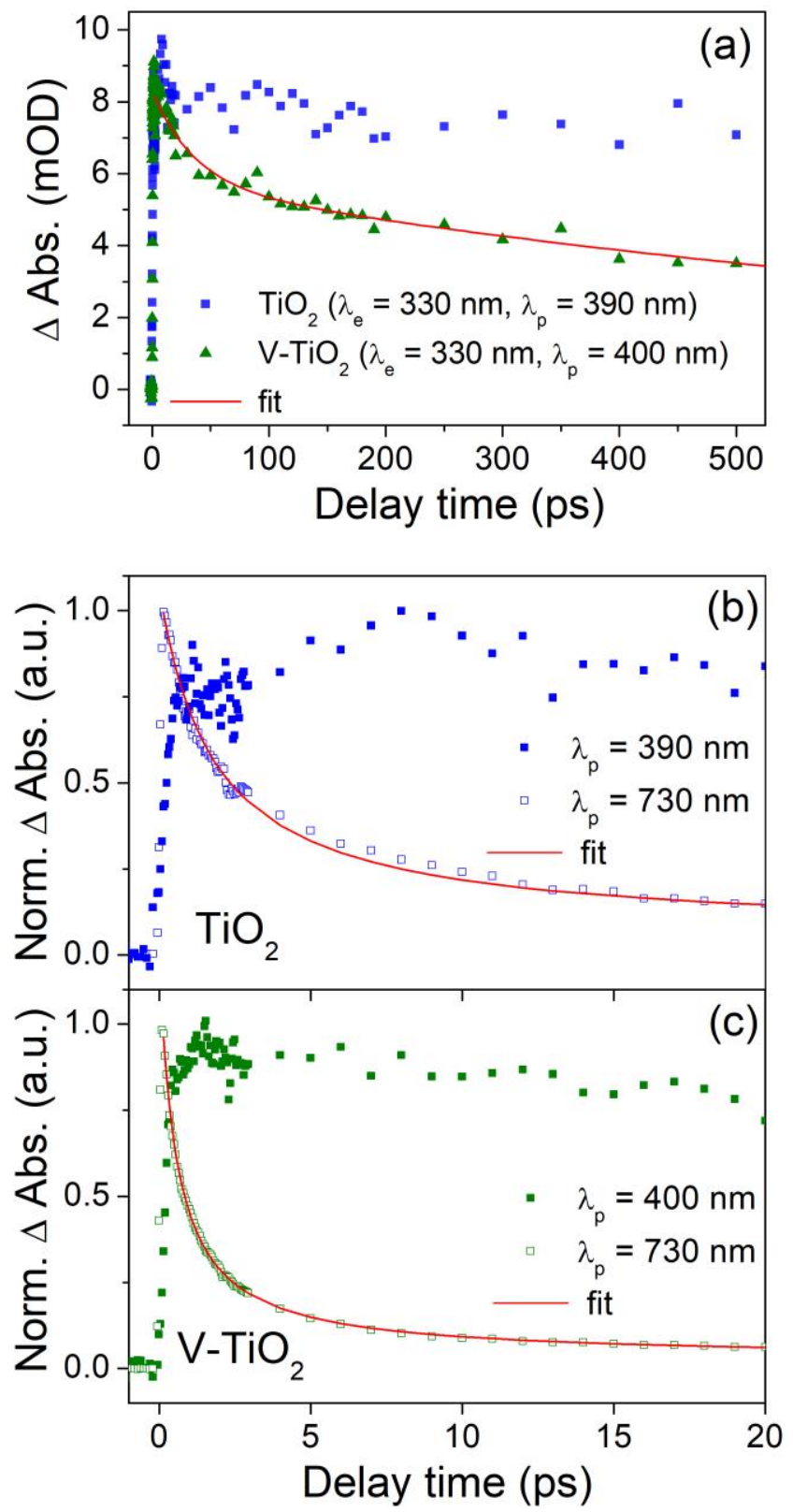

Figure 3: (a) TH signal time traces for undoped (blue squares) and V-doped (green triangles) $\mathrm{TiO}_{2} \mathrm{NPs}$ extracted from the data in Figure $1\left(\lambda_{\mathrm{e}}=330 \mathrm{~nm}\right)$. The red solid line is the best fit of the $\mathrm{V}-\mathrm{TiO}_{2} \mathrm{NPs}$ with a sum of two exponentials with characteristic times $\tau_{h 1}$ and $\tau_{h 2}$. (b) Comparison between the TH (filled squares) and $\mathrm{E}$ (empty squares) time traces for undoped $\mathrm{TiO}_{2} \mathrm{NPs}$ following photoexcitation at $330 \mathrm{~nm}$. The red solid line displays the best fit for the E time trace according to Equation 2. (c) Same as (b) for V-TiO ${ }_{2} \mathrm{NPs}$. For the best fit parameters, see Table I.

The two widely separated time scales observed for the $E$ signal reflect profoundly different decay mechanisms. The fast decay with second-order kinetics hints at electron-hole recombination, which is expected under our conditions of strong excitation $\left(1.8 \mathrm{~mJ} / \mathrm{cm}^{2}\right)$. The fluence-dependent study reported in Figure $\mathrm{S} 6$ supports this interpretation by showing that the decay slows down with decreasing pulse energy. This is in agreement with results of Tamaki et al. that observed second-order decay of the E signal within 100 ps after ultrabandgap irradiation under strong excitation conditions [30]. One may wonder which kind of holes take part in this process. In fact, Figure 3b,c clearly shows that over the first 10 ps, where the E signal drops by $\sim 80 \%$ and $\sim 90 \%$ for $\mathrm{TiO}_{2}$ and $\mathrm{V}-\mathrm{TiO}_{2}$, respectively, the $\mathrm{TH}$ signal is nearly constant in $\mathrm{TiO}_{2} \mathrm{NPs}$ and decreases by only $\sim 15 \%$ in $\mathrm{V}-\mathrm{TiO}_{2} \mathrm{NPs}$. Therefore, the surface-trapped holes seem not to be involved $\left(\mathrm{TiO}_{2}\right)$ or only marginally involved $\left(\mathrm{V}-\mathrm{TiO}_{2}\right)$ in the recombination. This observation leads us to suggest that the 
electrons recombine mainly with holes that do not contribute a clearly identifiable TA signal within our explored wavelength range. These may be shallowly trapped holes or free holes that remain in the NPs due to saturation of the surface hole traps under strong excitation.

The slower exponential decay with characteristic time $\tau_{e}$ in the 100 s of ps range (see Table I) was also observed by Tamaki et al. in the weak excitation limit [28]. They demonstrated that this dynamics reflects the relaxation of free electrons and shallowly trapped electrons to deep traps that do not contribute to the TA spectrum because of a very small optical absorption cross section. We can therefore subdivide the dynamics of charge carriers generated by strong ultrabandgap excitation into the following processes:

1) Holes migration and trapping on the surface of the NPs takes place in $\sim 230 \mathrm{fs}$ and leads to saturation of surface hole traps.

2) Recombination of free and shallowly trapped electrons with holes, mainly those that are not surfacetrapped, starts immediately after excitation and proceeds with second-order kinetics over a few tens of ps.

3) When only surface-trapped holes remain, the dynamics of residual electrons becomes similar to the one observed under weak excitation conditions: relaxation into deep traps with time $\tau_{e} \sim 220 \mathrm{ps}$ is the dominant mechanism. This process yields an efficient electron-hole separation and explains the long-lived TH signal, in agreement with literature results in absence of hole scavengers [2,26,28,32].

Electron scavenging by oxygen is not expected to influence the dynamics on such a short time scale. In fact, the reaction of electrons with oxygen takes place on a much longer time interval, which ranges from $100 \mathrm{~ns}$ for surface-trapped electrons to several ms for bulk electrons $[2,4,26]$.

The influence of V-doping on the aforementioned charge carrier dynamic after ultrabandgap irradiation can be summarized as follows:

i) V-doping affects neither the initial concentration of photo-excited carriers nor the migration and trapping of holes in $\sim 230 \mathrm{fs}$ on the surface of the NPs;

ii) $\quad V$-doping accelerates by a factor of $\sim 3$ (see parameter $k C$ in Table I) the second-order recombination kinetics that characterizes the fast decay of the $E$ signal;

iii) V-doping does not significantly alter the relaxation time of free or shallowly trapped electrons to deeper traps (see parameter $\tau_{e}$ in Table I).

iv) $\quad V$-doping reduces the lifetime of surface-trapped holes, the population of which decays according to a double exponential law in $\mathrm{V}-\mathrm{TiO}_{2} \mathrm{NPs}$. We suggest that the short time $\tau_{h 1}=36$ ps characterizes the recombination with free electrons -still available in this time interval- whereas the long time $\tau_{h 2}=1030 \mathrm{ps}$ can be ascribed to slower recombination with the deeply trapped electrons mentioned in iii).

Clearly, charge carriers prone to recombination in a few tens of ps are of limited relevance to most photocatalytic reactions, which require electron-hole separation and long lifetimes. Therefore, the connection between the V-doping effects on TA spectra and on photocatalytic properties should mainly address the long-lived reactive species. In this respect, item iv) above suggests that V-doping -at least in the present concentration- may have a negative effect on UV photocatalysis. This conclusion is supported by IPCE measurements presented later on. However, we will later see that V-doping induces photocatalytic activity and photoelectrochemical water splitting in a visible range, where pure $\mathrm{TiO}_{2} \mathrm{NPs}$ are completely inactive. 


\subsection{Transient absorption spectroscopy: longer wavelength (400 and $530 \mathrm{~nm}$ ) excitation}

We now describe measurements performed with $\lambda_{e}=400 \mathrm{~nm}$ and $530 \mathrm{~nm}$, at which wavelengths the difference between the optical absorbance of $\mathrm{TiO}_{2}$ and $\mathrm{V}-\mathrm{TiO}_{2} \mathrm{NPs}$ is very significant. With $\lambda_{e}=400 \mathrm{~nm}$ some transitions between the tails of the valence and conduction bands in undoped $\mathrm{TiO}_{2}$ are still possible while with $\lambda_{e}=530 \mathrm{~nm}$ undoped $\mathrm{TiO}_{2}$ is transparent and thus only features related to $\mathrm{V}$ are probed in $\mathrm{V}-\mathrm{TiO}_{2} \mathrm{NPs}$.

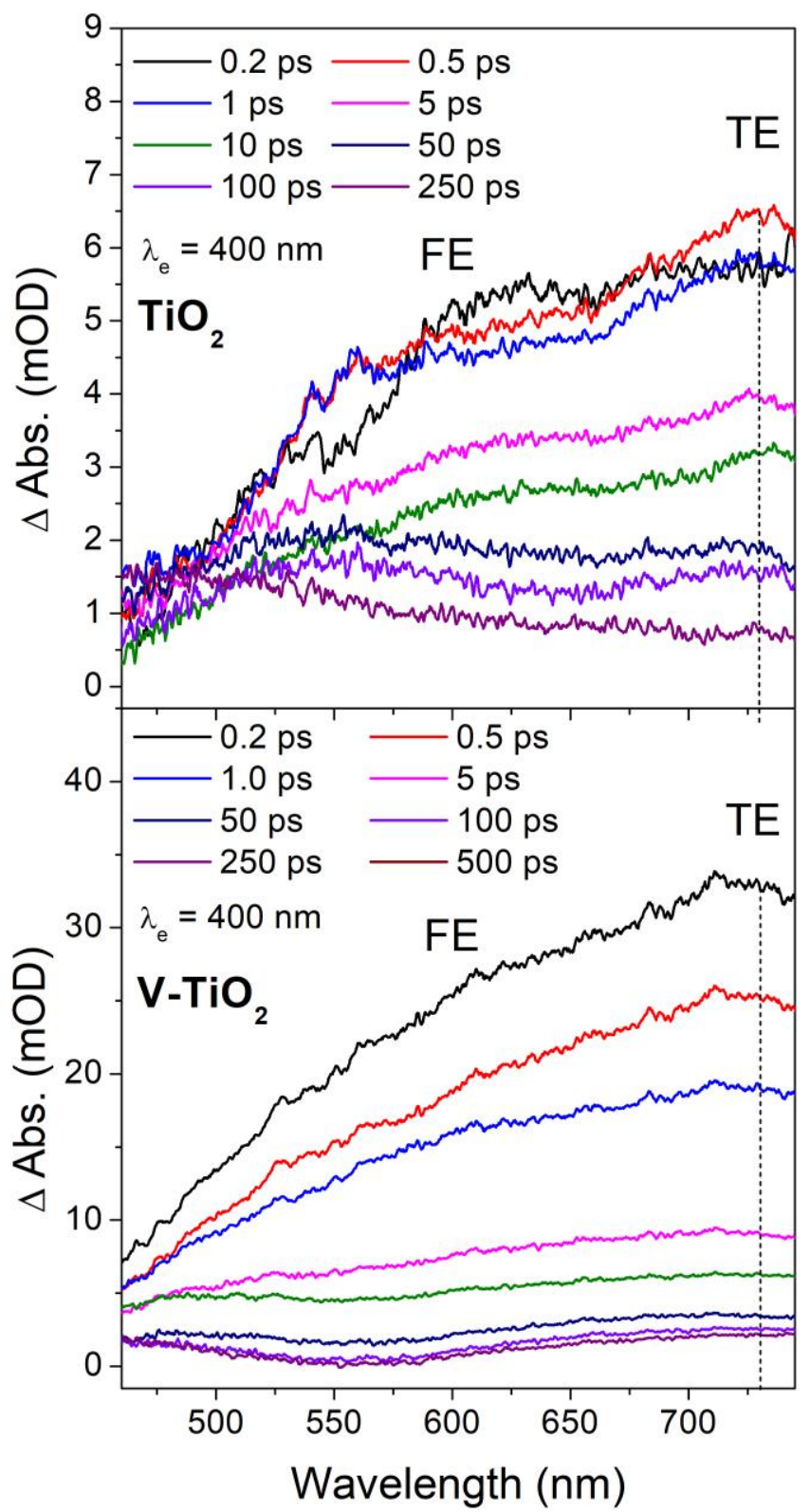

Figure 4: Transient absorption spectra of $\mathrm{TiO}_{2}$ (top) and $\mathrm{V}-\mathrm{TiO}_{2}$ (bottom) NPs samples with $\lambda_{e}=400 \mathrm{~nm}$ at different delay times.

TA spectra excited with $\lambda_{e}=400 \mathrm{~nm}$ for $\mathrm{TiO}_{2}$ and $\mathrm{V}-\mathrm{TiO}_{2} \mathrm{NPs}$ are reported as a function of $\lambda_{p}$ for selected time delays in the range $t=0.2-500 \mathrm{ps}$ in Figure 4 . The same data are displayed in 2 dimensions as a function of $\left(\lambda_{p}, t\right)$ in Figure S4 of the supplementary material. At this excitation wavelength, the TH feature is not observable since it overlaps with the pump beam, while the remaining part of the spectra are qualitatively similar to those observed for ultrabandgap excitation. The main doping-induced difference is clearly the initial intensity of the measured transient signal that for $\mathrm{V}-\mathrm{TiO}_{2} \mathrm{NPs}$ at $\lambda_{p}=730 \mathrm{~nm}$ is a factor of $\sim 5$ higher. This is consistent with the stronger optical absorbance of $\mathrm{V}-\mathrm{TiO}_{2} \mathrm{NPs}$ at $400 \mathrm{~nm}$ shown in Figure $\mathrm{S} 2$. The time traces of the E signal of both samples can be fitted well using the model Equation (2) already applied for 
excitation at $\lambda_{e}=330 \mathrm{~nm}$. The best fits are shown in Figure 5 and the corresponding parameters are reported in Table I. The results corroborate the interpretation of the carrier dynamics proposed for ultrabandgap excitation. In fact, we notice that the ratio $A_{\text {exp }} / A_{2 n d}$ increases at $\lambda_{e}=400 \mathrm{~nm}$ compared to $\lambda_{e}=330 \mathrm{~nm}$ by a factor of 4.7 for $\mathrm{TiO}_{2} \mathrm{NPs}$ and of 4.0 for $\mathrm{V}-\mathrm{TiO}_{2} \mathrm{NPs}$. This indicates that a smaller fraction of electrons is involved in fast second-order recombination processes and that the slower exponential relaxation to deep traps gains importance. Furthermore, the rates of the second-order kinetics are slower compared to $\lambda_{e}=330$ $\mathrm{nm}$. Both results are consistent with the lower initial concentration of charge carriers after excitation at $\lambda_{e}=400 \mathrm{~nm}$, qualitatively represented by the initial value of the $\mathrm{E}$ signal. The effects of V-doping on the characteristic decay times are similar to the case of ultrabandgap excitation: the second-order kinetics are speeded up (see $k C$ parameter in Table I), suggesting that $\mathrm{V}$ favors recombination, while the relaxation time to deep bulk traps does not change (see parameter $\tau_{e}$ in Table I). The slightly higher $\tau_{e}$ values for both samples compared to $\lambda_{e}=330 \mathrm{~nm}$ may indicate that the relaxation time is longer for electrons with lower energy. As mentioned above, it was not possible to detect the TH signal. However, it is reasonable to assume that a situation similar to the case $\lambda_{e}=330 \mathrm{~nm}$ is at play, i.e. that long-lived surface-trapped holes are present and that $\mathrm{V}$-doping favors their recombination.

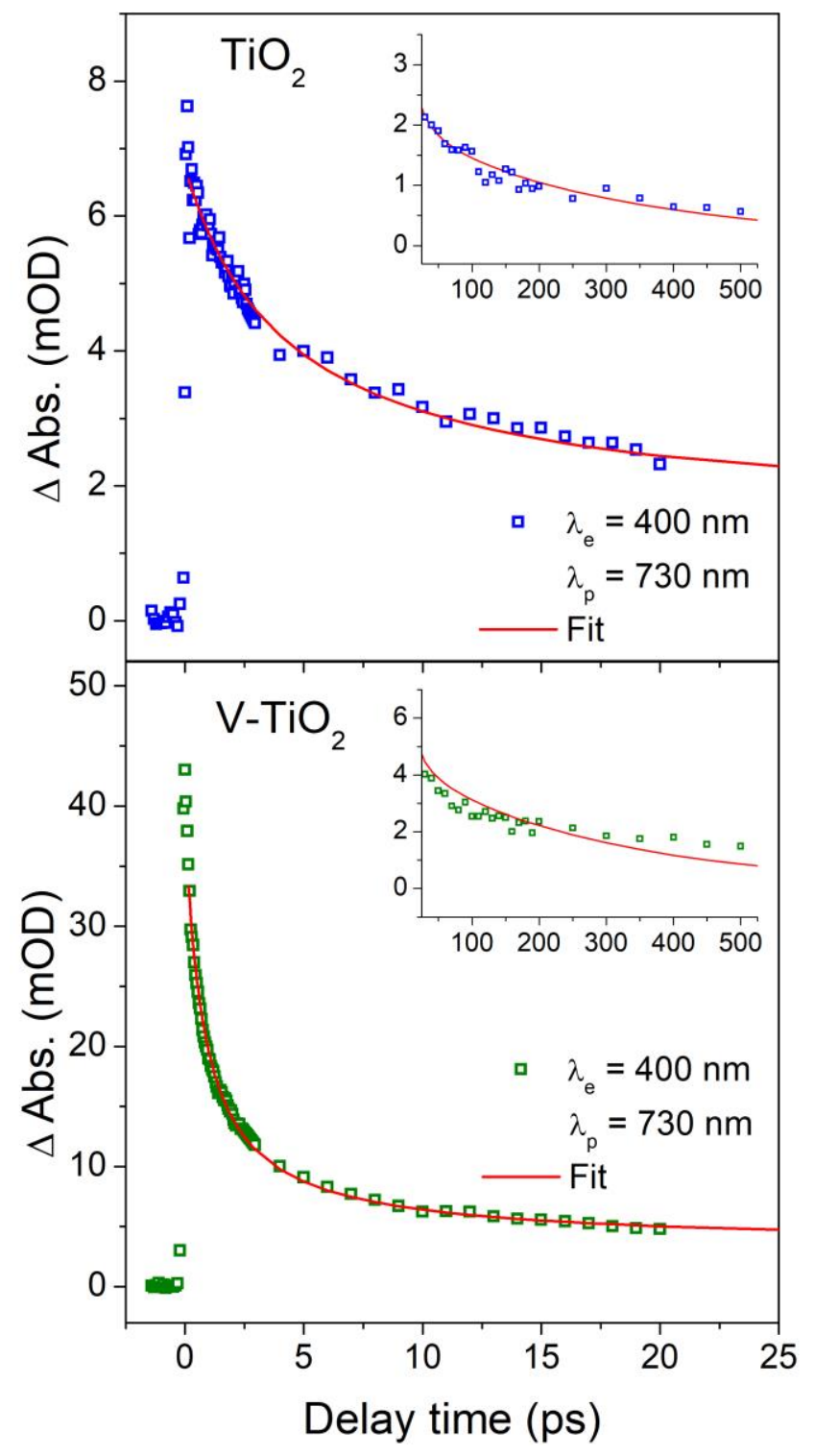

Figure 5: Comparison of the E signal time traces (at $\lambda_{p}=730 \mathrm{~nm}$ ) for undoped (top) and V-doped (bottom) $\mathrm{TiO}_{2}$ NPs extracted from the data in Figure $4\left(\lambda_{\mathrm{e}}=400 \mathrm{~nm}\right)$. The best fits according to Equation 2 are displayed as red solid lines. The inset reports the same data over the extended 25-525 ps time interval. 
For excitation at $\lambda_{e}=530 \mathrm{~nm}$ it was impossible to measure any $\mathrm{TA}$ signal in the $\mathrm{TiO}_{2} \mathrm{NPs}$. However, as shown in Figure 6, using $7 \mathrm{~mJ} / \mathrm{cm}^{2}$ pulses we were able to observe the time trace of a weak E signal in V-TiO 2 NPs. The corresponding TA spectra at selected delay times, restricted to $\lambda_{p}>600 \mathrm{~nm}$ due to overlapping with the pump beam and to the very weak intensity, are displayed in Figure S7. The best fit of the E signal according to Equation (2) is displayed in Figure 6 and the corresponding parameters are reported in Table I. The amplitudes $A_{2 n d}$ and $A_{\text {exp }}$ are rather small and exhibit a similar value of about $1 \mathrm{mOD}$, in qualitative agreement with the previous remark that $A_{\text {exp }} / A_{2 n d}$ increases with decreasing concentration of photoexcited electrons. The characteristic relaxation time $\tau_{e}=480 \mathrm{ps}$ is slightly longer than after excitation at $\lambda_{e}=$ $400 \mathrm{~nm}$.

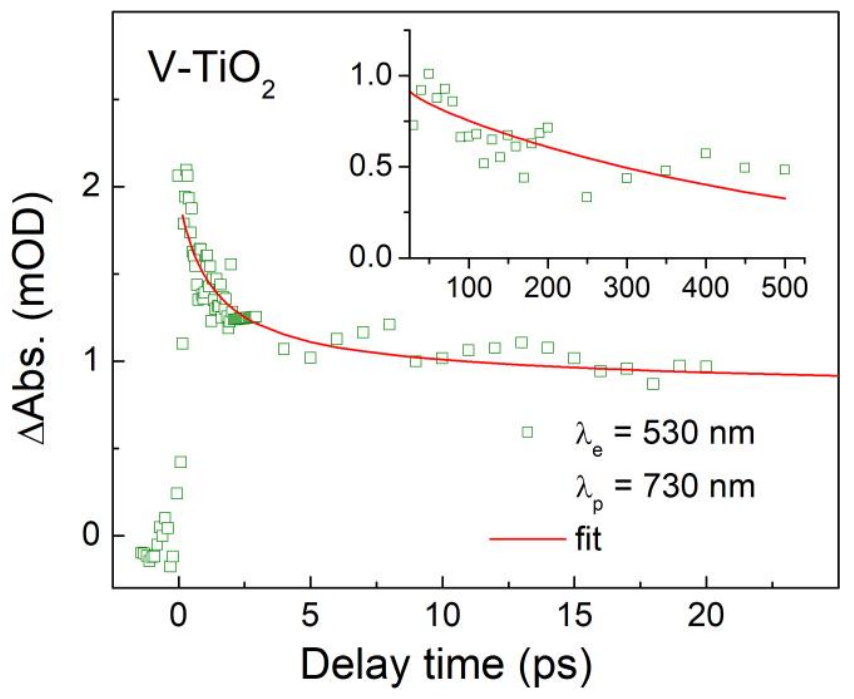

Figure 6: Time trace of the E signal $\left(\lambda_{p}=730 \mathrm{~nm}\right)$ and relative best fit obtained with $7 \mathrm{~mJ} / \mathrm{cm}^{2}$ and $\lambda_{\mathrm{e}}=530$ $\mathrm{nm}$ pump pulse in $\mathrm{V}-\mathrm{TiO}_{2} \mathrm{NPs}$. The inset displays the same data and fit in the extended 25-525 ps interval.

The final important message is that irradiation of $\mathrm{V}-\mathrm{TiO}_{2} \mathrm{NPs}$ in the $400-530 \mathrm{~nm}$ range is capable of generating long-lived electrons with relaxation dynamics similar to that observed after irradiation at $330 \mathrm{~nm}$. This suggests that photon absorption, also at the low energy of $2.34 \mathrm{eV}(530 \mathrm{~nm})$, results in electron excitation into the conduction band, followed by shallow trapping and relaxation. Since $2.34 \mathrm{eV}$ is well below the band gap of pure $\mathrm{TiO}_{2}(3.0-3.2 \mathrm{eV})$, the initial electron state must be an intra-gap state that originates with Vdoping. This also means that upon photon absorption a transition of a substitutional dopant cation from a $\mathrm{V}^{4+}$ to $a \mathrm{~V}^{5+}$ oxidation state must take place, leaving a hole on the $\mathrm{V}$ site. This picture is in full agreement with the results of our recent XANES experiment on the same V-TiO ${ }_{2} \mathrm{NPs}$, in which we observed a blue-shift of the $\checkmark$ K-edge during laser irradiation at $532 \mathrm{~nm}$ [45]. We estimated that the photo-excited $\mathrm{V}^{5+}$ has an extremely long lifetime of $\sim 0.8 \mathrm{~ms}$. In the same experiment we highlighted a concomitant red-shift of the Ti K-edge, suggesting that the electron remains trapped at a defective Ti state. The high-energy-resolution analysis of the XANES lineshape indicated that such Ti traps are mostly localized on the NPs surface.

Irradiation at $400 \mathrm{~nm}(3.1 \mathrm{eV})$ represents an intermediate case, in which electronic excitations both from the valence band and from intra-gap $V$-related states are possible. The much higher absorption and TA signal in $\mathrm{V}-\mathrm{TiO}_{2}$ compared to $\mathrm{TiO}_{2}$, however, suggests that the latter plays the dominant role.

The relevant question now is whether this picture corresponds to a tangible photocatalytic activity in the visible spectral range. We will address this issue in the following section.

\subsection{Visible light photocatalysis and photoelectrochemistry}

Figure 7a displays optical absorption spectra of $\mathrm{NO}_{2}-\mathrm{C}_{6} \mathrm{H}_{4}-\mathrm{CHO}$ and of $\mathrm{NH}_{2}-\mathrm{C}_{6} \mathrm{H}_{4}-\mathrm{CHO}$, which show absorption maxima at $264 \mathrm{~nm}$ and $312 \mathrm{~nm}$ respectively. De-aerated suspensions of $\mathrm{V}-\mathrm{TiO}_{2} \mathrm{NPs}$ containing $\mathrm{NO}_{2}-\mathrm{C}_{6} \mathrm{H}_{4}-\mathrm{CHO}$ were illuminated with visible light $(\lambda>450 \mathrm{~nm})$ and the reduction of the nitro group in $\mathrm{NO}_{2}-\mathrm{C}_{6} \mathrm{H}_{4}-\mathrm{CHO}$ to 
$\mathrm{NH}_{2}-\mathrm{C}_{6} \mathrm{H}_{4}-\mathrm{CHO}$ was monitored. In order to gain information about the conversion of $\mathrm{NO}_{2}-\mathrm{C}_{6} \mathrm{H}_{4}-\mathrm{CHO}$ to $\mathrm{NH}_{2}-$ $\mathrm{C}_{6} \mathrm{H}_{4}-\mathrm{CHO}$, we tracked the evolution of the $\mathrm{A}_{312} / \mathrm{A}_{264}$ ratio with increasing irradiation time. Figure $7 \mathrm{~b}$ shows that this ratio slowly increases during visible light illumination $(\lambda>450 \mathrm{~nm})$ of $\mathrm{V}-\mathrm{TiO}_{2} \mathrm{NPs}$. This result is an indication that this photocatalyst is able to reduce the nitro group using photoexcited electrons from visible absorbing states. From a mechanistic point of view, it has been demonstrated that the protons required to form the $\mathrm{NH}_{2}$ group are provided by the dissociative adsorption of sacrificial $\mathrm{C}_{3} \mathrm{H}_{8} \mathrm{O}$ (isopropanol, 2- $\mathrm{Pr}-\mathrm{OH}$ ) on the NPs surface and its subsequent oxidation into $\mathrm{C}_{3} \mathrm{H}_{6} \mathrm{O}$ (acetone) [52]. Further details on the mechanism of $\mathrm{H}^{+}$formation are provided in the Supplementary Material. We also remark that, although in a photocatalytic process oxidation and reduction reactions take place on the same NP, a perfect synchronization of electron and proton transfer is not necessary. In fact, $\mathrm{TiO}_{2}$-based NPs can act as temporary reservoirs of electrons, giving rise to electron accumulation in the conduction band followed by trapping in states below the CBM.
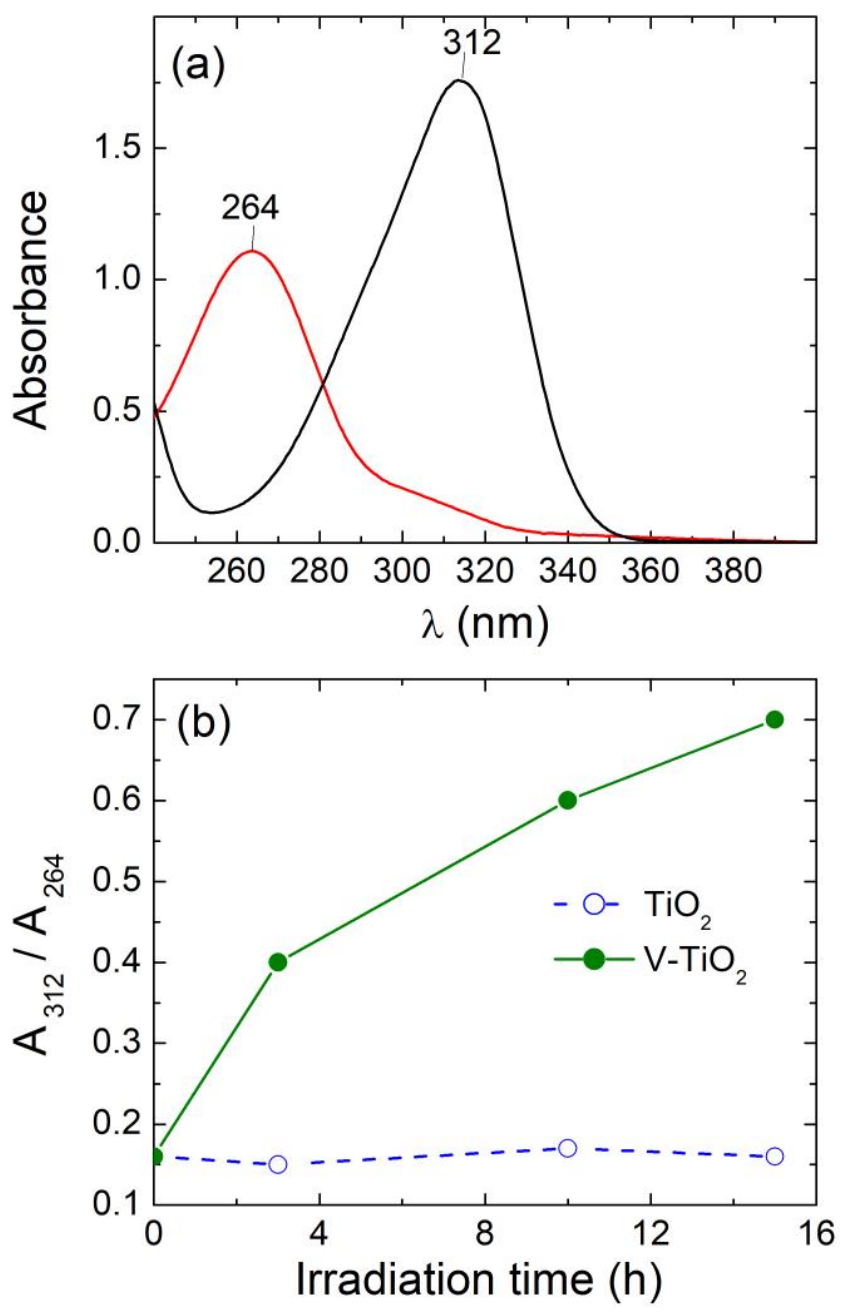

Figure 7: (a) Absorption spectra of $\mathrm{NO}_{2}-\mathrm{C}_{6} \mathrm{H}_{4}-\mathrm{CHO}$ (black) and $\mathrm{NH}_{2}-\mathrm{C}_{6} \mathrm{H}_{4}-\mathrm{CHO}$ (blue) (both around $1 \times 10^{-4} \mathrm{M}$ ) dissolved in a $\mathrm{CH}_{3} \mathrm{CN} / \mathrm{C}_{3} \mathrm{H}_{8} \mathrm{O}(4 / 1)$ solvent mixture. (b) The absorbance ratio as a function of irradiation time for $\mathrm{V}-\mathrm{TiO}_{2}$ (full circles) and $\mathrm{TiO}_{2}$ (empty circles) NPs. Values of absorbance are taken at the wavelengths of the two compounds that correspond to the absorbance maxima shown in (a).

An important point to note is that the ratio $\mathrm{A}_{312} / \mathrm{A}_{264}$ is constant when undoped $\mathrm{TiO}_{2} \mathrm{NPs}$ are illuminated by visible light under exactly the same photocatalytic conditions (Figure $7 \mathrm{~b}$, empty circles). This result indicates that undoped $\mathrm{TiO}_{2} \mathrm{NPs}$ alone are not able to perform any reduction on $\mathrm{NO}_{2}-\mathrm{C}_{6} \mathrm{H}_{4}-\mathrm{CHO}$ under $\lambda>450 \mathrm{~nm}$ illumination, confirming that photoactive states introduced by $\mathrm{V}$-doping are mandatory for triggering such 
photocatalytic reaction. Control experiments in the dark and in the absence of photocatalyst confirm that the reaction proceeds only under the simultaneous presence of both $\mathrm{V}-\mathrm{TiO}_{2} \mathrm{NPs}$ and visible light (Figure S8).

If the spectral range of the incident light is extended in the UV, e.g. by using a $\lambda>360 \mathrm{~nm}$ filter, the photocatalytic reduction takes place in few minutes [52] and a significant difference between undoped and V-doped $\mathrm{TiO}_{2}$ NPs can no longer be detected.

Electron paramagnetic resonance (EPR) spin-trapping experiments show that, for both samples, the formation of radicals coming from 2-propanol takes place immediately after illumination in the wavelength range $\lambda>360 \mathrm{~nm}$ (Figure S9). Under these conditions, the photocatalytic behaviour of $\mathrm{V}-\mathrm{TiO}_{2}$ is qualitatively the same as for undoped $\mathrm{TiO}_{2}$, being dominated by transitions from the valence to the conduction band. Differently, under excitation at $\lambda>450 \mathrm{~nm}$, EPR signals were not detected (Figure S9). While for $\mathrm{TiO}_{2}$ the absence of an EPR signal is consistent with the lack of optical absorption in this range, for $\mathrm{V}-\mathrm{TiO}_{2}$ it suggests that the average concentration of radicals is below the sensitivity limit of a typical EPR spin trapping experiment. In fact one can consider that photogenerated radicals are not usually quantitatively trapped and that the paramagnetic adduct between radical and spin trap is continuously formed and consumed. This is consistent with the long times (hours) necessary to observe the photocatalytic reduction process, which is clearly related to the cumulative effect of the radicals.

The IPCE spectra of photoanodes made with $\mathrm{TiO}_{2}$ and $\mathrm{V}-\mathrm{TiO}_{2} \mathrm{NPs}$ are reported in Figure 8. The low IPCE values for both samples are likely due to the poor ohmic contact achieved with the preparation method. Here we are interested in comparing the spectral shapes. Two features allow us to establish a connection with the TA spectroscopy results. The first is that $\mathrm{V}-\mathrm{TiO}_{2} \mathrm{NPs}$ exhibit a higher IPCE in the $\lambda \gtrsim 360 \mathrm{~nm}$ range. In particular, photoelectrochemical water splitting in the $430-480 \mathrm{~nm}$ range is still possible with $\mathrm{V}-\mathrm{TiO}_{2} \mathrm{NPs}$ whereas the IPCE of $\mathrm{TiO}_{2} \mathrm{NPs}$ is almost zero. A connection with the enhanced optical absorbance (Figure S2) and TA signal (Figures 5 and 6 ) in this wavelength range is straightforward, but the result also brings information on the energy level of the $\mathrm{V}$ dopant, as discussed later on. The second is that $\mathrm{V}-\mathrm{TiO}_{2} \mathrm{NPs}$ have lower IPCE in the UV range $\lambda \lesssim 350 \mathrm{~nm}$. This may reflect the doping-enhanced recombination of surface trapped holes with deeply trapped electrons previously connected with the decay of the TH signal in UV-irradiated $\mathrm{V}-\mathrm{TiO}_{2} \mathrm{NPs}$ (see $\tau_{h}$ in Table I). In fact, with decreasing wavelength and increasing extinction coefficient, the incident radiation is absorbed closer to the electrolytic solution and farther from the ITO back contact. This means that on average the electrons must travel a longer distance across the film, increasing the probability of recombination before reaching the ITO layer.

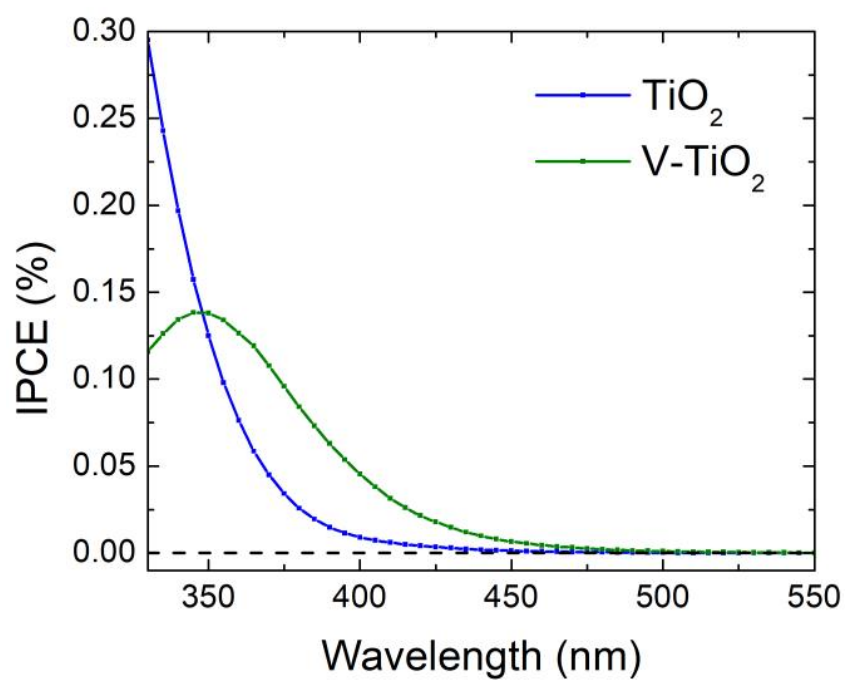

Figure 8: IPCE spectra of photoanodes prepared with $\mathrm{TiO}_{2}$ and $\mathrm{V}-\mathrm{TiO}_{2} \mathrm{NPs}$. 
The IPCE spectra were also measured in the $\mathrm{CH}_{3} \mathrm{CN} / \mathrm{C}_{3} \mathrm{H}_{8} \mathrm{O}(4 / 1)$ mixture used for the photocatalytic tests with $\mathrm{LiClO}_{4} 0.1 \mathrm{M}$ as electrolyte. No significant changes were detected compared to the results shown in Figure 8 for $0.1 \mathrm{M} \mathrm{KOH}$ in water.

\subsection{Correlation between charge carrier dynamics and photocatalysis}

The combination of TA spectra and photocatalytic / photoelectrochemical measurements leads to a unified picture of the charge carrier dynamics after visible light irradiation and of the dopant energy level in $\mathrm{V}-\mathrm{TiO}_{2}$ NPs, as schematized in Figure 9 and described in the following.

The photocatalytic reaction shown in Figure $7 \mathrm{~b}$, albeit slow, testifies that electrons photoexcited by visible light irradiation of $\mathrm{V}-\mathrm{TiO}_{2} \mathrm{NPs}$ possess suitable energies and lifetimes to reduce the nitro group in solution. The TA spectral shape and the $\mathrm{E}$ signal relaxation dynamics indicate that visible absorbing electrons are photoexcited into the conduction band. At present, we do not know the characteristic time $\tau_{I T}$, over which interfacial electron transfer from the $\mathrm{V}-\mathrm{TiO}_{2} \mathrm{NPs}$ to the solution takes place. If $\tau_{I T} \ll \tau_{e}$ (see Table I), there is no time for the electrons to relax into deep traps and the reaction consumes shallow-trapped electrons. Vice versa, if $\tau_{I T} \gg \tau_{e}$, the electrons relax first into deep traps, and subsequently reduce the molecules in solution. Intermediate situations are clearly possible. The red-shift of the $\mathrm{Ti} \mathrm{K}$ edge under stationary visible-light irradiation observed by XANES [45] allows us to assign the deep trapping to $\mathrm{Ti}_{s}^{4+}+e^{-} \rightarrow \mathrm{Ti}_{s}^{3+}$ at a defective surface site $\mathrm{Ti}_{s}$. A previous electrochemical study showed that $-\mathrm{NO}_{2}$ reduction takes place at about $0.5 \mathrm{eV}$ below the CBM [52]. Since sub-bandgap visible light cannot promote electronic transitions from the valence to the conduction band, the initial electron state must be an intra-gap state associated with $\mathrm{V}$, which is incorporated as a substitutional $\mathrm{V}^{4+}$ cation in the lattice of both rutile and anatase $[43,44]$. There is a significant spread in the calculated energy level of the electronic state localized on $\mathrm{V}^{4+}$, which was reported between $0.7 \mathrm{eV}[16,20]$ and $1.36 \mathrm{eV}[21]$ below the CBM. However, our results show that it must lie deeper than suggested by calculations. In fact, IPCE measurements tell us that the hole $h_{V}^{+}$left on the $\mathrm{V}$ site after photoexcitation: $\mathrm{V}^{4+}+h v \rightarrow \mathrm{V}^{5+}+e_{C B}^{-}=h_{V}^{+}+e_{C B}^{-}$has a suitable potential to drive oxygen evolution. Taking into account the $\mathrm{pH}$ conditions $(\mathrm{pH}=13)$ and the known $\mathrm{TiO}_{2}$ band edge positions in aqueous environment [53], we conclude that the oxygen evolution potential corresponds to an energy level at $1.5 \mathrm{eV}$ below CBM. It is therefore reasonable to assume that the actual quasi-Fermi level of the trapped holes in the $\mathrm{V}-\mathrm{TiO}_{2} \mathrm{NPs}$ is somewhat lower in energy with respect to such value, in order to provide sufficient overpotential for oxygen evolution. The optical absorbance spectra provide further information in this respect: in fact, Figure S2 shows that absorption extinguishes at $\sim 550 \mathrm{~nm}(\sim 2.2 \mathrm{eV})$, proving that there are no absorbing electrons closer than $\sim 2.2 \mathrm{eV}$ to the CBM. We may therefore locate the $\mathrm{V}$ dopant level at $\sim 2.2$ $\mathrm{eV}$ below the CBM. Such an estimate is consistent with static absorbance, TA spectroscopy and IPCE measurements, and is also in agreement with an early experimental investigation by electron paramagnetic resonance, which located the $\mathrm{V}^{4+}$ level at $\sim 2.1 \mathrm{eV}$ below the CBM [8]. According to this picture, one would expect photoelectrochemical water splitting to be possible also in the $480-550 \mathrm{~nm}$ range, where instead Figure 8 shows almost zero IPCE. However, the photocurrent may drop below the detection limit due to the much weaker excitation in the IPCE setup compared to TA spectroscopy and to the aforementioned ohmic losses in the NPs-assembled photoanodes.

To close the cycle, we suggest that the hole $h_{V}^{+}$on the $V$ site migrates to a trapping site on the NPs surface, where it promotes the oxidation of $\mathrm{C}_{3} \mathrm{H}_{8} \mathrm{O}$ to $\mathrm{C}_{3} \mathrm{H}_{6} \mathrm{O}$, liberating two $\mathrm{H}^{+}$ions. This reaction provides the protons that are needed to form the $\mathrm{NH}_{2}$ group. The net result is thus a transfer of electrons and protons from the sacrificial $\mathrm{C}_{3} \mathrm{H}_{8} \mathrm{O}$ to $\mathrm{NO}_{2}-\mathrm{C}_{6} \mathrm{H}_{4}-\mathrm{CHO}$ mediated by the $\mathrm{V}-\mathrm{TiO}_{2}$ nanoparticle photocatalysts. 


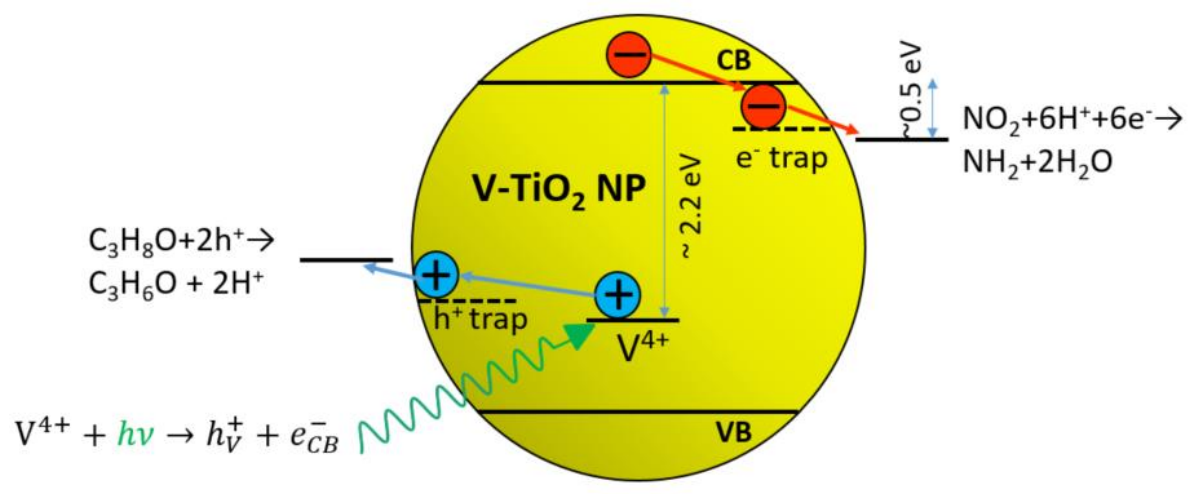

Figure 9: Schematic representation of the photocatalytic reduction of 4-nitrobenzaldehyde by $\mathrm{V}-\mathrm{TiO}_{2} \mathrm{NPs}$ under visible irradiation.

\section{Conclusions}

This study sheds light on the carrier dynamics, electronic structure and photocatalytic properties of V-doped $\mathrm{TiO}_{2} \mathrm{NPs}$ compared to undoped ones. The primary findings, achieved thanks to a combination of transient absorption spectroscopy and photocatalytic/photoelectrochemical characterization, can be summarized as follows:

i) Under strong excitation at $\lambda_{\mathrm{e}}=330$ and $400 \mathrm{~nm}$, a fast electron-hole recombination according to a secondorder kinetics is observed, the recombination rate being higher in V-doped NPs. The electrons that survive recombination undergo a slower relaxation into deep traps;

ii) Valence band holes migrate to and are trapped on the surface over an ultrafast time scale ( $\sim 230 \mathrm{fs}$ ). Trapped holes exhibit a long lifetime $>500$ ps in undoped NPs, whereas V-doping seems to accelerate their recombination with trapped electrons;

iii) In V-doped NPs only, the photoexcitation of electrons under irradiation at $\lambda_{e}=530 \mathrm{~nm}$ is observed. We associate this peculiar feature of V-doped NPs with an intra-gap state localized on $\mathrm{V}^{4+}$ substitutional cations, from which electrons can be photo-excited into the CB by sub-band gap irradiation. We locate this level at about $2.2 \mathrm{eV}$ below the CBM;

iv) The presence of charge carriers photo-excited from visible absorbing states in V-doped NPs corresponds to a clear photocatalytic activity in a spectral region where undoped $\mathrm{TiO}_{2} \mathrm{NPs}$ are inactive. $\mathrm{V}-\mathrm{TiO}_{2} \mathrm{NPs}$ are able to reduce the nitro group $\mathrm{NO}_{2}$ in 4-nitrobenzaldehyde under visible light irradiation $(\lambda>450 \mathrm{~nm})$, and water splitting with $\mathrm{V}-\mathrm{TiO}_{2}$ photoanodes is possible up to $\lambda \sim 480 \mathrm{~nm}$.

Future studies may investigate the dependence of photoactivity on the V-doping level with the aim to optimize the competition between positive and negative features induced by doping, i.e. enhanced visible light absorption vs accelerated electron-hole recombination.

\section{Acknowledgements}

This research was funded by the Italian Ministry of Research (MIUR) within PRIN-2015 Project No. NEWLI2015CL3APH. 


\section{$\underline{\text { References }}$}

[1] M.A. Henderson, A surface science perspective on TiO2 photocatalysis, Surf. Sci. Rep. 66 (2011) 185297. doi:10.1016/j.surfrep.2011.01.001.

[2] J. Schneider, M. Matsuoka, M. Takeuchi, J. Zhang, Y. Horiuchi, M. Anpo, D.W. Bahnemann, Understanding TiO 2 Photocatalysis: Mechanisms and Materials, Chem. Rev. 114 (2014) 9919-9986. doi:10.1021/cr5001892.

[3] N. Serpone, A. V. Emeline, V.K. Ryabchuk, V.N. Kuznetsov, Y.M. Artem'ev, S. Horikoshi, Why do Hydrogen and Oxygen Yields from Semiconductor-Based Photocatalyzed Water Splitting Remain Disappointingly Low? Intrinsic and Extrinsic Factors Impacting Surface Redox Reactions, ACS Energy Lett. 1 (2016) 931-948. doi:10.1021/acsenergylett.6b00391.

[4] A. Fujishima, X. Zhang, D.A. Tryk, TiO2 photocatalysis and related surface phenomena, Surf. Sci. Rep. 63 (2008) 515-582. doi:10.1016/j.surfrep.2008.10.001.

[5] J. Tang, J.R. Durrant, D.R. Klug, Mechanism of Photocatalytic Water Splitting in TiO2. Reaction of Water with Photoholes , Importance of Charge Carrier Dynamics , and Evidence for Four-Hole Chemistry, J. Am. Chemi. 130 (2008) 13885-13891. doi:10.1021/ja8034637.

[6] H. Zhang, G. Chen, D.W. Bahnemann, Photoelectrocatalytic materials for environmental applications, J. Mater. Chem. 19 (2009) 5089-5121. doi:10.1039/b821991e.

[7] R. Asahi, T. Morikawa, T. Ohwaki, K. Aoki, Y. Taga, Visible-light photocatalysis in nitrogen doped titanium oxides, Science (80-. ). 293 (2001) 269-271.

[8] K. Mizushima, M. Tanaka, A. Asai, S. lida, J.B. Goodenough, Impurity levels of iron-group ions in TiO2(II), J. Phys. Chem. Solids. 40 (1979) 1129-1140. doi:10.1016/0022-3697(79)90148-3.

[9] O. Elbanna, P. Zhang, M. Fujitsuka, T. Majima, Facile preparation of nitrogen and fluorine codoped TiO 2 mesocrystal with visible light photocatalytic activity, Appl. Catal. B Environ. 192 (2016) 80-87. doi:10.1016/j.apcatb.2016.03.053.

[10] W. Choi, A. Termin, M.R. Hoffmann, The Role of Metal lon Dopants in Quantum-Sized TiO2: Correlation between Photoreactivity and Charge Carrier Recombination Dynamics, J. Phys. Chem. 98 (1994) 13669-13679. doi:10.1021/j100102a038.

[11] J. Choi, H. Park, M.R. Hoffmann, Effects of single metal-ion doping on the visible-light photoreactivity of TiO2, J. Phys. Chem. C. 114 (2010) 783-792. doi:10.1021/jp908088x.

[12] R. Asahi, T. Morikawa, H. Irie, T. Ohwaki, Nitrogen-doped titanium dioxide as visible-light-sensitive photocatalyst: Designs, developments, and prospects, Chem. Rev. 114 (2014) 9824-9852. doi:10.1021/cr5000738.

[13] M. Graetzel, R.F. Howe, Electron paramagnetic resonance studies of doped titanium dioxide colloids, J. Phys. Chem. 94 (1990) 2566-2572. doi:10.1021/j100369a064.

[14] D. Dvoranová, V. Brezová, M. Mazúr, M.A. Malati, Investigations of metal-doped titanium dioxide photocatalysts, Appl. Catal. B Environ. 37 (2002) 91-105. doi:10.1016/S0926-3373(01)00335-6.

[15] R. Jaiswal, N. Patel, D.C. Kothari, A. Miotello, Improved visible light photocatalytic activity of TiO2 codoped with Vanadium and Nitrogen, Appl. Catal. B Environ. 126 (2012) 47-54. doi:10.1016/j.apcatb.2012.06.030.

[16] N. Patel, R. Jaiswal, T. Warang, G. Scarduelli, A. Dashora, B.L. Ahuja, D.C. Kothari, A. Miotello, Efficient photocatalytic degradation of organic water pollutants using $\mathrm{V}-\mathrm{N}$-codoped TiO2 thin films, Appl. Catal. B Environ. 150-151 (2014) 74-81. doi:10.1016/j.apcatb.2013.11.033. 
[17] B. Tian, C. Li, F. Gu, H. Jiang, Y. Hu, J. Zhang, Flame sprayed V-doped TiO2 nanoparticles with enhanced photocatalytic activity under visible light irradiation, Chem. Eng. J. 151 (2009) 220-227. doi:10.1016/J.CEJ.2009.02.030.

[18] W.-C. Lin, Y.-J. Lin, Effect of Vanadium(IV)-Doping on the Visible Light-Induced Catalytic Activity of Titanium Dioxide Catalysts for Methylene Blue Degradation, Environ. Eng. Sci. 29 (2012) 447-452. doi:10.1089/ees.2010.0350.

[19] W. Zhou, Q. Liu, Z. Zhu, J. Zhang, Preparation and properties of vanadium-doped TiO 2 photocatalysts, J. Phys. D. Appl. Phys. 43 (2010) 035301. doi:10.1088/0022-3727/43/3/035301.

[20] T. Umebayashi, T. Yamaki, H. Itoh, K. Asai, Analysis of electronic structures of $3 \mathrm{~d}$ transition metaldoped TiO2 based on band calculations, J. Phys. Chem. Solids. 63 (2002) 1909-1920. doi:10.1016/S0022-3697(02)00177-4.

[21] J. Osorio-Guillén, S. Lany, A. Zunger, Atomic Control of Conductivity Versus Ferromagnetism in WideGap Oxides Via Selective Doping: V, Nb, Ta in Anatase <math display="inline" $><$ msub $>$ $<\mathrm{mi}>\mathrm{TiO}</ \mathrm{mi}><\mathrm{mn}>2</ \mathrm{mn}></$ msub $></$ math $>$, Phys. Rev. Lett. 100 (2008) 036601. doi:10.1103/PhysRevLett.100.036601.

[22] G. Rothenberger, J. Moser, M. Graetzel, N. Serpone, D. Sharma, Charge carrier trapping and recombination dynamics in small semiconductor particles, J. Am. Chem. Soc. 107 (1985) 8054-8059. doi:10.1021/ja00312a043.

[23] N. Serpone, D. Lawless, R. Khairutdinov, Size Effects on the Photophysical Properties of Colloidal Anatase TiO2 Particles: Size Quantization versus Direct Transitions in This Indirect Semiconductor?, J. Phys. Chem. 99 (1995) 16646-16654. doi:10.1021/j100045a026.

[24] D. Colombo, R. Bowman, Does interfacial charge transfer compete with charge carrier recombination? A femtosecond diffuse reflectance investigation of TiO2 nanoparticles, J. Phys. Chem. 3654 (1996) 18445-18449. doi:10.1021/jp9610628.

[25] N. Serpone, D. Lawless, R. Khairutdinov, E. Pelizzetti, Subnanosecond relaxation dynamics in TiO2 colloidal sols (Particle sizes $\mathrm{Rp}=1.0-13.4 \mathrm{~nm}$ ). Relevance to heterogenous photocatalysis, J. Phys. Chem. 99 (1995) 16655-16661. doi:10.1021/j100045a027.

[26] T. Yoshihara, R. Katoh, A. Furube, Y. Tamaki, M. Murai, K. Hara, S. Murata, H. Arakawa, Identification of Reactive Species in Photoexcited Nanocrystalline TiO2 Films by Wide-Wavelength-Range (400-2500 nm) Transient Absorption Spectroscopy, J. Phys. Chem. B. 108 (2004) 3817-3823. doi:10.1021/jp031305d.

[27] X. Yang, N. Tamai, How fast is interfacial hole transfer? In situ monitoring of carrier dynamics in anatase TiO2 nanoparticles by femtosecond laser spectroscopy, Phys. Chem. Chem. Phys. 3 (2001) 3393-3398. doi:10.1039/b101721g.

[28] Y. Tamaki, A. Furube, M. Murai, K. Hara, R. Katoh, M. Tachiya, Dynamics of efficient electron-hole separation in $\mathrm{TiO} 2$ nanoparticles revealed by femtosecond transient absorption spectroscopy under the weak-excitation condition., Phys. Chem. Chem. Phys. 9 (2007) 1453-1460. doi:10.1039/b617552j.

[29] M. Murai, Y. Tamaki, A. Furube, K. Hara, R. Katoh, Reaction of holes in nanocrystalline TiO2 films evaluated by highly sensitive transient absorption spectroscopy, Catal. Today. 120 (2007) 214-219. doi:10.1016/J.CATTOD.2006.07.048.

[30] Y. Tamaki, K. Hara, R. Katoh, M. Tachiya, A. Furube, Femtosecond Visible-to-IR Spectroscopy of TiO 2 Nanocrystalline Films: Elucidation of the Electron Mobility before Deep Trapping †, J. Phys. Chem. C. 113 (2009) 11741-11746. doi:10.1021/jp901833j. 
[31] A. Furube, T. Asahi, H. Masuhara, H. Yamashita, M. Anpo, Charge carrier dynamics of standard TiO2 catalysts revealed by femtosecond diffuse reflectance spectroscopy, J. Phys. Chem. B. 103 (1999) 3120-3127. doi:10.1021/jp984162h.

[32] D.W. Bahnemann, M. Hilgendorff, R. Memming, Charge carrier dynamics at TiO2 particles: reactivity of free and trapped holes, J. Phys. Chem. B. 101 (1997) 4265-4275. doi:10.1021/jp9639915.

[33] A.L. Linsebigler, A.L. Linsebigler, J.T. Yates Jr, G. Lu, G. Lu, J.T. Yates, Photocatalysis on TiO2 Surfaces: Principles, Mechanisms, and Selected Results, Chem. Rev. 95 (1995) 735-758. doi:10.1021/cr00035a013.

[34] T. Berger, M. Sterrer, O. Diwald, E. Knözinger, D. Panayotov, T.L. Thompson, J.T. Yates, Light-Induced Charge Separation in Anatase TiO 2 Particles, J. Phys. Chem. B. 109 (2005) 6061-6068. doi:10.1021/jp0404293.

[35] R.F. Howe, M. Gratzel, EPR observation of trapped electrons in colloidal titanium dioxide, J. Phys. Chem. 89 (1985) 4495-4499. doi:10.1021/j100267a018.

[36] D.E. Skinner, D.P. Colombo, J.J. Cavaleri, R.M. Bowman, Femtosecond Investigation of Electron Trapping in Semiconductor Nanoclusters, J. Phys. Chem. 99 (1995) 7853-7856. doi:10.1021/j100020a003.

[37] J. Sun, Y. Yang, J.I. Khan, E. Alarousu, Z. Guo, X. Zhang, Q. Zhang, O.F. Mohammed, Ultrafast carrier trapping of a metal-doped titanium dioxide semiconductor revealed by femtosecond transient absorption spectroscopy, ACS Appl. Mater. Interfaces. 6 (2014) 10022-10027. doi:10.1021/am5026159.

[38] K. Gopinadhan, B. Kumar, N. Palina, M. Motapathula, I. Pallecchi, T.P. Sarkar, Y. Zhihua, J.Q. Chen, A. Annadi, A. Rana, A. Srivastava, D. Marré, J. Chen, A. Ariando, S. Dhar, A. Rusydi, T. Venkatesan, Effect of $\mathrm{Nb}$ and Ta substitution on donor electron transport and ultrafast carrier dynamics in anatase TiO 2 thin films, J. Mater. Chem. C. 3 (2015) 6329-6333. doi:10.1039/C5TC01061F.

[39] K.I. Yamanaka, T. Ohwaki, T. Morikawa, Charge-carrier dynamics in Cu- or Fe-loaded nitrogen-doped TiO2 powder studied by femtosecond diffuse reflectance spectroscopy, J. Phys. Chem. C. 117 (2013) 16448-16456. doi:10.1021/jp404431z.

[40] K. Yamanaka, T. Morikawa, Charge-Carrier Dynamics in Nitrogen-Doped TiO2 Powder Studied by Femtosecond Time-Resolved Diffuse Reflectance Spectroscopy, J. Phys. Chem. C. 116 (2012) 12861292. doi:10.1021/jp209210u.

[41] M. Salmi, N. Tkachenko, R.J. Lamminmäki, S. Karvinen, V. Vehmanen, H. Lemmetyinen, Femtosecond to nanosecond spectroscopy of transition metal-doped TiO2 particles, J. Photochem. Photobiol. A Chem. 175 (2005) 8-14. doi:10.1016/j.jphotochem.2005.03.022.

[42] S. Ikeda, N. Sugiyama, B. Pal, G. Marcí, L. Palmisano, H. Noguchi, K. Uosaki, B. Ohtani, Photocatalytic activity of transition-metal-loaded titanium(IV) oxide powders suspended in aqueous solutions: Correlation with electron-hole recombination kinetics, Phys. Chem. Chem. Phys. 3 (2001) 267-273. doi:10.1039/b008028o.

[43] G. Rossi, M. Calizzi, V. Di Cintio, S. Magkos, L. Amidani, L. Pasquini, F. Boscherini, Local Structure of v Dopants in TiO<inf >2</inf> Nanoparticles: X-ray Absorption Spectroscopy, Including Ab-Initio and Full Potential Simulations, J. Phys. Chem. C. 120 (2016). doi:10.1021/acs.jpcc.5b12045.

[44] Z. El Koura, G. Rossi, M. Calizzi, L. Amidani, L. Pasquini, A. Miotello, F. Boscherini, XANES study of vanadium and nitrogen dopants in photocatalytic TiO 2 thin films, Phys. Chem. Chem. Phys. 20 (2018) 221-231. doi:10.1039/C7CP06742A.

[45] G. Rossi, M. Calizzi, L. Amidani, A. Migliori, F. Boscherini, L. Pasquini, Element-specific channels for 
the photoexcitation of V-doped Ti O 2 nanoparticles, Phys. Rev. B. 96 (2017) 045303. doi:10.1103/PhysRevB.96.045303.

[46] L. Amidani, A. Naldoni, M. Malvestuto, M. Marelli, P. Glatzel, V. Dal Santo, F. Boscherini, Probing long-lived plasmonic-generated charges in $\mathrm{TiO}<\mathrm{inf}>2</ \mathrm{inf}>/ \mathrm{Au}$ by high-resolution $\mathrm{x}$-ray absorption spectroscopy, Angew. Chemie - Int. Ed. 54 (2015). doi:10.1002/anie.201412030.

[47] M.H. Rittmann-Frank, C.J. Milne, J. Rittmann, M. Reinhard, T.J. Penfold, M. Chergui, Mapping of the photoinduced electron traps in TiO2 by picosecond x-ray absorption spectroscopy, Angew. Chemie Int. Ed. 53 (2014) 5858-5862. doi:10.1002/anie.201310522.

[48] Y. Obara, H. Ito, T. Ito, N. Kurahashi, S. Thürmer, H. Tanaka, T. Katayama, T. Togashi, S. Owada, Y. Yamamoto, S. Karashima, J. Nishitani, M. Yabashi, T. Suzuki, K. Misawa, Femtosecond time-resolved X-ray absorption spectroscopy of anatase $\mathrm{TiO}_{2}$ nanoparticles using XFEL, Struct. Dyn. 4 (2017) 044033. doi:10.1063/1.4989862.

[49] L. Tian, L. di Mario, V. Zannier, D. Catone, S. Colonna, P. O’Keeffe, S. Turchini, N. Zema, S. Rubini, F. Martelli, Ultrafast carrier dynamics, band-gap renormalization, and optical properties of ZnSe nanowires, Phys. Rev. B. 94 (2016) 165442. doi:10.1103/PhysRevB.94.165442.

[50] I. Fratoddi, A. Cartoni, I. Venditti, D. Catone, P. O'Keeffe, A. Paladini, F. Toschi, S. Turchini, F. Sciubba, G. Testa, C. Battocchio, L. Carlini, R. Proietti Zaccaria, E. Magnano, I. Pis, L. Avaldi, Gold nanoparticles functionalized by rhodamine B isothiocyanate: A new tool to control plasmonic effects, J. Colloid Interface Sci. 513 (2018) 10-19. doi:10.1016/J.JCIS.2017.11.010.

[51] B. Enright, D. Fitzmaurice, Spectroscopic Determination of Electron and Hole Effective Masses in a Nanocrystalline Semiconductor Film, J. Phys. Chem. 100 (1996) 1027-1035. doi:10.1021/jp951142w.

[52] A. Molinari, A. Maldotti, R. Amadelli, Probing the Role of Surface Energetics of Electrons and their Accumulation in Photoreduction Processes on TiO 2, Chem. - A Eur. J. 20 (2014) 7759-7765. doi:10.1002/chem.201402039.

[53] B. Enright, C. Redmond, D. Fitzmaurice, Spectroscopic Determination of Flatband Potentials for Polycrystalline Ti02 Electrodes in Mixed Solvent Systems, J. Phys. Chem. 98 (1994) 6195-6200. https://pubs.acs.org/doi/pdf/10.1021/j100075a023 (accessed March 28, 2018). 